\title{
II. Strukturelle Kontexte: Konturen städtischer Erinnerungsräume und Profile öffentlicher Denkmalstifter
}

\section{Kompetenzarrangements und Verfahrensmuster}

So wenig Deutungshoheiten und die Verteilung von Symbolmacht in administrativen Reglements aufgehen, so sehr stellen letztere doch Bedingungsrahmen für die Praxis öffentlicher Denkmalerrichtung dar, die im Vergleich unterschieden werden müssen. Denkmäler wurden in den Kapitalen sowohl vom Staat als auch von den Städten selbst oder privaten Trägern errichtet. Bevor der Ursprung jeweiliger Initiativen geklärt wird, sind Kompetenzarrangements vergleichend $\mathrm{zu}$ betrachten, die das Prozedere organisatorisch und verwaltungsrechtlich kanalisierten. Strukturelle Kontexte interessieren dabei hinsichtlich der Frage, inwiefern die Kompetenzverteilung unter den beteiligten Instanzen und Personen zwischen den Kapitalen differierte und in welchem Maße folglich an dieser Stelle bereits Deutungsmonopole gesichert oder umkämpft erscheinen. Die Vorgehensweisen der Denkmalstifter werden also zunächst überblicksartig und auf der Suche nach Verfahrensmustern und deren Varianten dargestellt, ohne daß alle Monumente zur Sprache kommen könnten, die später für die Analyse wichtig werden.

\subsection{Paris}

Während des Zweiten Empire konnten Denkmalerrichtungen in Paris nur mit dem Plazet des Empereur aufgestellt werden'. Seit Etablierung der Dritten Republik war eine Autorisierung durch den Staatspräsidenten erforderlich, der von Denkmalkomitees über den Préfet de la Seine und den Ministre de l'Intérieur angegangen werden mußte. Über die Frage des Standortes entschied zunächst der Besitzer des für die Denkmalerrichtung von den Initiatoren vorgesehenen und erbetenen Areals, in dessen Obhut das Monument nach der Einweihung häufig überging. Darüber hinaus blieb aber das präfektoriale Dekret unerläßlich. Da ein Großteil des städtischen Bodens in Paris der Stadt gehörte, spielte sie in Gestalt ihres Repräsentativorgans, des Conseil Municipal de la Ville de Paris, zumindest bei der Frage der Zuerkennung von Standorten eine zentrale Rolle. Hiervon ausgenommen waren grundsätzlich Monumente, die im Jardin du Luxembourg und im Jardin des Tuileries errichtet werden sollen, weil hier der Staat die Bodenrechte hielt ${ }^{2}$.

' Erkennbar wurde das Verfahren z.B. anläßlich der Plazierung des Denkmals für General Ney 1853, vgl. dazu weiter unten.

2 Vgl. Hargrove, Les statues de Paris, S. 280, Anm. 21. 
Mit dem Préfet de la Seine, der seit der napoleonischen Verwaltungsreform zu Beginn des Jahrhunderts zugleich in der Funktion des Pariser Bürgermeisters einer hierarchischen Verwaltungsstruktur in der Kapitale vorstand, nahm ein direkt dem Ministre de l'Intérieur unterstellter, staatsnaher Funktionsträ$\mathrm{ger}^{3}$ an der Spitze der in Divisionen untergliederten Préfecture eine wichtige Position im Verfahren ein. Selten involviert wurde sein Gegenpart in der doppelköpfig angeordneten Verwaltungsstruktur, der ebenfalls dem Innenministerium zugeordnete und für Fragen der öffentlichen Sicherheit zuständige Préfet de Police. Die verwaltungstechnische Reduktion des Conseil Municipal nach 1848 zu einem vom Empereur bestellten Organ minimierte zugleich die Rolle des Gremiums für die Denkmalerrichtungen während des Zweiten Empire ${ }^{4}$. Zwischen Kriegsniederlage und der Commune 1871 verstärkten sich Forderungen nach der Zulassung gewählter Körperschaften und setzten schließlich das Gouvernement de la Défense Nationale unter Handlungsdruck ${ }^{5}$. Unter Beibehaltung der staatlichen Anbindung und der erheblichen Kompetenzreichweite der beiden Präfekten, die an den Sitzungen des Conseil Municipal teilnahmen und stimmberechtigt waren, entsandten ab April 1871 die 20 Arrondissements je vier Conseillers auf drei Jahre nach absolutem Mehrheitswahlrecht in den nun 80-köpfigen Conseil Municipal, der seit 1886 öffentlich tagte $^{6}$. Daß im Conseil Municipal wie dem Conseil général de la Seine, in dem auch Vertreter der beiden Arrondissements und suburbanen Kantone SaintDenis und Sceaux vertreten waren ${ }^{7}$, in der Regel die republikanische Linke dominierte, machte sich in Initiativen und Kritik aus den Reihen vor allem des ersten Gremiums im Zuge der öffentlichen Denkmalpolitik wiederholt bemerkbar.

Faktisch blieb die öffentliche Repräsentations- und Denkmalpolitik während des Zweiten Empire eine Art Reservatrecht des Empereur. So war die Initiative zu dem 1853 errichteten Denkmal für Marschall Ney zwar ursprünglich vom Gouvernement Provisoire von 1848 ausgegangen ${ }^{8}$; noch vor dem Staatsstreich

3 Vgl. WILLMS, Paris, S. 161.

4 Napoleon III. ernannte alle 5 Jahre die 36, ab 1860 nach Aufstockung der Zahl Pariser Arrondissements von 12 auf 20 insgesamt 60 Conseil-Mitglieder. Vgl. Alfred FIERRO, Histoire et dictionnaire de Paris, Paris 1996, S. 325-326; Maurice FÉLIX, Le régime administratif et financier de la Ville de Paris et du Département de la Seine, Bd. 1, Paris o. J., S. 107-110; DERS., Le régime, Bd. 3, Paris o. J., S. 4f., 9f.; Bernard Rouleau, Paris: Histoire d'un espace, Paris 1997, S. 358; WILLMS, Paris, S. 369.

5 Vgl. Willms, Paris, S. 429.

6 Vgl. FIERRO, Histoire, S. 331; FÉLIX, Le régime, Bd. 1, S. 142f.; DERS., Le régime, Bd. 3, S. $96-106$

7 Vgl. FÉLIX, Le régime, Bd. 1, S. 142f. Erst 1893 fand eine Aufstockung auf 12 Vertreter für Saint-Denis und 9 für Sceaux statt, der Conseil général de la Seine umfasste entsprechend seitdem 101, ab 1908 dann 102 Mitglieder.

8 Vgl. undatierter Rapport au Prince Président de la République aus dem Innenministerium, AN $F^{21} 583$ Dossier II: Monument du Maréchal Ney, 1850-1854, place de 
hatte Napoleon das Projekt aber aufgegriffen ${ }^{9}$ und blieb zusammen mit dem Innenminister die zentrale Instanz des Verfahrens ${ }^{10}$. Da sich der anvisierte Standort am Observatoire in städtischem Besitz befand, mußte dennoch formal der Pariser Stadtrat ersucht werden, das Terrain bereitzustellen ${ }^{11}$.

Anders als in Berlin oder London wirkte sich die Zäsur von 1871 in Paris auf das Verfahren öffentlicher Denkmalerrichtungen am stärksten aus. An die Stelle des Empereur trat nun als Letztinstanz im Genehmigungsverfahren der französische Staatspräsident. Der übliche Verfahrensweg, der dann in dieser Phase von den Initiatorengruppen zu beschreiten war, zeichnete sich u.a. im Falle des Denkmals für den Revolutionär Ledru-Rollin Anfang der 1880er Jahre ab. Das Komitee beantragte demzufolge in der Regel vom Innenminister die Genehmigung des Projekts, der sich seinerseits an den Seinepräfekten wandte, um mit Angaben zur Besetzung des Komitees und zum Stand bisheriger Vorbereitungen diejenigen Informationen in Erfahrung zu bringen, die die ministerielle Entscheidungsgrundlage bilden mußten ${ }^{12}$. Der Préfet lieferte nicht nur die gewünschten Daten, sondern formulierte auch ein Votum und machte darauf aufmerksam, daß das Komitee auf das ministerielle Plazet angewiesen war, um einen Wettbewerb für das Denkmal ausschreiben zu können ${ }^{13}$. Nach Fürsprache auch des Innenministers gegenüber dem Staatspräsidenten lag das Dekret zur Bewilligung der Denkmalerrichtung schließlich vor ${ }^{14}$ und wurde vom Innenminister dem Präfekten zurückgemeldet ${ }^{15}$.

Der Conseil Municipal war immer automatisch am Verfahren beteiligt, wenn Denkmalsetzungen auf städtischem Grund anvisiert waren; die präsidiale Autorisierungspflicht galt dann aber weiter ${ }^{16}$. Zum Testfall für die Austarierung

l'Observatoire/Construction de la statue et de son piédestal [up] und Le Siècle, 9. Dezember 1853, S. 1.

9 Rapport au Président de la République des Innenministers Barrot vom 5. März 1850, AN $\mathrm{F}^{21} 583$ Dossier II: Monument du Maréchal Ney/Construction [up].

${ }^{10}$ Rapport à Monsieur le Ministre Sécretaire d'État au département de l'Intérieur vom Directeur des Beaux-Arts am 27. Mai 1852, AN F 583 Dossier II: Monument du Maréchal Ney/Construction. Ein ähnliches Verfahren lag der Errichtung des Eugène de BeauharnaisDenkmals von 1863 zugrunde, vgl. Schreiben des Innenministers Billault an Napoleon III. und Dekret des Empereur vom 16. November 1857, AN F ${ }^{\text {lc }}$ I 168 [up].

1 Vgl. Nachricht des Innenministers an den Préfet de la Seine vom 1. Oktober 1852, AN F ${ }^{21}$ 583 Dossier II: Monument du Maréchal Ney/Construction.

12 Vgl. Brief des Innenministers an den Préfet de la Seine vom März 1882, DAC Dossier Ledru-Rollin [up].

13 Vgl. Schreiben des Préfet de la Seine an den Innenminister vom 22. Mai 1882, AN F ${ }^{\text {ic }}$ I 168 Dossier: mars 1882-février 1884, érection d'une statue à Ledru-Rollin, place Voltaire [up].

14 Vgl. Décret du 9 juin 1882, AN F ${ }^{\text {lc }}$ I 168 Dossier, ibid.

$15 \mathrm{Vgl}$. Schreiben des Innenministers an den Préfet de la Seine vom 12. Juni 1882, AN F ${ }^{\text {lc }}$ I 168 Dossier, ibid.

16 Vgl. so z.B. beim Denkmal für den Quarantehuitard Louis Blanc; vgl. Extrait du registre des Procès-Verbaux du Conseil Municipal vom 24. Juni 1885 und Dekret des Ministre de 
von Kompetenzen zwischen staatlichen Entscheidungsträgern und Conseil Municipal gerieten die Planungen für ein Voltaire-Denkmal. Im Zuge der Vorbereitungen einer Feier des hundertjährigen Todestages von Voltaire am 30. Mai 1878 war der Plan von einem Comité central du centenaire de Voltaire aufgebracht worden, das die Feierlichkeiten organisierte. Vom Conseil erbat es die Zuerkennung eines Standortes für ein Denkmal in der Hauptstadt, das man bereits in Auftrag gegeben hatte ${ }^{17}$. Daß der Conseil sich mehrheitlich gewogen zeigte und bereits in Frage kommende Standorte erörterte ${ }^{18}$, trug ihm eine Rüge Innenministers De Marcère ein. Bemängelt wurde, daß sich der Conseil Kompetenzen weit über das ihm zustehende Maß hinaus aneigne, indem er öffentliche Denkmäler ohne Rücksprache mit der Regierung zu dekretieren versuche und über die Gestaltung eines öffentlichen Platzes entscheide. Fragen der "fêtes nationales politiques« reklamierte der Innenminister demgegenüber energisch als Reservatrecht der »autorité centrale«. Aus diesen Gründen war der Préfet de la Seine gehalten, die Beschlußvorlage des Conseil nicht passieren zu lassen und dem Denkmalvorhaben nicht stattzugeben ${ }^{19}$. Die Unterstützung des Conseil für die Denkmalinitiative war damit allerdings nur vorübergehend abgeblockt. Statt dessen unternahm er nun seinerseits Anstrengungen, in Eigenregie zu einem Voltairemonument zu gelangen ${ }^{20}$. Erst Jahre später wurde der Plan realisiert ${ }^{21}$, weil der Conseil bei allem programmatischen Bekenntnis zur Voltaire-Statue von verhandlungsbedingten Ermüdungserscheinungen nicht frei war.

Wettbewerbsausschreibungen gingen, unabhängig von staatlichen oder städtischen Initiatoren, nicht selten mit festen ikonographischen Programmvorgaben einher. So waren im Wettbewerbsprogramm des Conseil général de la Seine für die Allegorie der Défense de Paris zur Erinnerung an die Belagerung von Paris 1871 neben Angaben zu Standort und exakter Höhe des Monuments $^{22}$ auch bereits die programmatische Festlegung enthalten, daß ein En-

l'Intérieur vom 28. Oktober 1886, AN F ${ }^{\text {tc }}$ I 169 Dossier: 24 juin 1885-27 octobre 1886, Érection d'une statue à Louis Blanc (place Mongue).

17 Vgl. Lettre d'invitation, séance du 11 mai, in: Conseil Municipal de la Ville de Paris, Procès-Verbaux [künftig: CMPV], Année 1878, S. 332.

18 Vgl. Proposition, séance du 11 mai, in: ibid. S. 332.

$19 \mathrm{Vgl}$. Lettre de M. le Ministre de l'Intérieur, séance du 11 mai, in: ibid. S. 396f. Vgl. dazu sehr viel ausführlicher Kapitel V im zweiten Teil dieser Arbeit.

20 Vgl. Programmes des concours, in: Conseil Municipal de la Ville de Paris, Rapports et Documents [künftig: CMRD], Année 1879, Imp. N90, Paris 1879, S. 13.

21 Vgl. Érection de la statue de Voltaire, Quai Malaquais, séance du 28 mars 1884, in: CMPV, Année 1884, $1^{\text {er }}$ sem., S. 676-682, hier S. 681f.

22 Vgl. Préfecture du Département de la Seine. Concours pour l'érection au rond-point de Courbevoie d'un Monument allégorique de la Défense de Paris en 1870, AP VR 161 Dossier: Concours pour l'érection au rond-point de Courbevoie d'un monument. Vgl. zum Wettbewerb auch Denise LAVALLE, Le monument de La Défense et la statuaire du XIX siècle, in: WELL, La perspective, S. 132-154. 
semble von zwei Figuren gezeigt werden sollte. Über die Auswahl von Entwürfen entschied eine Jury aus dem Préfet de la Seine als Präsident und acht Mitgliedern, davon drei Vertreter des Conseil général, zwei Delegierte der Administration und drei von den am Wettbewerb teilnehmenden Künstlern gewählte Kandidaten ${ }^{23}$. Das Gremium war am Ende des Verfahrens zur schriftlichen Niederlegung der Gründe für seine Wahl verpflichtet ${ }^{24}$, um so das Entscheidungsverfahren transparent zu gestalten. Auf einen Preisträger legte man sich wie in zahlreichen anderen Verfahren im Rahmen eines zweistufigen Auswahlprozederes fest, indem man zunächst unter 100 eingesandten 11 Modelle zur weiteren Ausarbeitung bestimmte und nach geraumer Zeit unter diesen das Siegermodell prämierte ${ }^{25}$. Auch an der Programmplanung für die Einweihungsfeier des Denkmals 1883 war eine von den Initiatoren bereitgestellte Kommission federführend beteiligt ${ }^{26}$.

\subsection{Berlin}

Öffentliche Denkmalerrichtungen in Berlin unterstanden grundsätzlich der Kontrolle des Monarchen, der zwar nicht in jedem Falle, aber durchaus intensiv von dieser Option Gebrauch machte. Der symbolpolitische entsprach dabei durchaus dem ebenfalls rigiden administrativen Zugriff seitens der Monarchie auf die Metropole: Seit 1828 oblag die Kommunalaufsicht über Berlin einschließlich der Kontrolle des Gemeindeetats, der Kontrolle über die Veräußerung von Grundstücken sowie baupolizeilicher Befugnisse dem Regierungspräsidenten in Potsdam und die Oberaufsicht damit zugleich dem preußischen Innenministerium. Zwar wurde Berlin 1875 aus der Verwaltung der Provinz Brandenburg herausgelöst und schließlich 1880/81 als eigener Verwaltungsbezirk etabliert, aber der Oberpräsident der brandenburgischen Provinz blieb in

${ }^{23} \mathrm{Vgl}$. Concours pour le monument de Courbevoie, éléction de 3 Jurés pour les artistes, AP VR 161 Dossier: Concours pour l'érection au rond-point.

${ }^{24}$ Vgl. ibid.

25 Vgl. Département de la Seine. Concours (...). Rapport présenté au nom du jury chargé du classement des esquisses, Paris 1879, ibid.; Concours (...) Rapport présenté au nom du Jury, Paris 1880, S. 4 ibid; Mémoire du Conseil Général an den Préfet de la Seine vom 26. Februar 1881, AP VR 161 Dossier: Monument de la Défense, Concours.

${ }^{26} \mathrm{Vgl}$. dazu und zum Folgenden Inauguration du monument allégorique de la Défense de Paris, Réunion préparatoire tenue le 16 Juillet, AP VR 161 Dossier: Inauguration du monument de Courbevoie; Commission chargée d'organiser l'inauguration (...), ProcèsVerbal, séance du 18 Juillet 1883, ibid. Bildprogrammatische Festlegungen und ein gestuftes Wettbewerbsverfahren prägten auch das Prozedere um die Républiquefigur, die auf Initiative des Conseil 1883 eingeweiht werden konnte. Vgl. Proposition, séance du 11 avril 1878, in: CMPV, Année 1878, S. 260-265; Rapport (...) sur le programme du concours, in: CMRD, Année 1879, Imp. $\mathrm{N}^{\circ} 17$. 
Personalunion Oberpräsident von Berlin und hatte hier die staatliche Aufsicht über Gemeindeangelegenheiten inne ${ }^{27}$.

Die institutionellen Voraussetzungen für eine eigenständige städtische Symbolpolitik waren auch in anderer Hinsicht ungünstig. Im Gefolge der Revolution verkleinerten sich nämlich die Handlungsspielräume der Stadtverordnetenversammlung ${ }^{28}$, die nach dem Dreiklassenwahlrecht abhängig von der Höhe entrichteter direkter Staats- und Gemeindesteuern gebildet wurde und vor allem von Vertretern des Handels- und Wirtschafts- wie des Bildungsbürgertums und leitenden Beamten geprägt war $^{29}$ : Zum einen war ihr der in der Regel von nationalliberalen und konservativen Kräften dominierte Magistrat überlegen, dessen Mitglieder wiederum von der Bestätigung durch die preußische Regierung abhingen ${ }^{30}$. Zum anderen standen ähnlich wie in Paris auch übergeordneten staatlichen Autoritäten Interventionsrechte in die hauptstädtischen Belange $\mathrm{zu}$, indem etwa der Berliner Bürgermeister vom preußischen König im Amt bestätigt werden mußte. Daß die Stadt über einen großen Teil der Straßen und öffentlichen Plätze verfügte ${ }^{31}$, war unter diesen Bedingungen keine Garantie für eine selbstbewußte Symbolpolitik ${ }^{32}$.

Umgekehrt lag im rigiden staatlichen Zugriff auf die kommunalen Belange Berlins nicht schon die komplette Instrumentalisierung der städtischen Organe beschlossen. Das zeigten schlaglichtartig die zahlreichen Konfliktkonstellationen, die sich zwischen den steuerungsbeflissenen staatlichen Institutionen und der durchaus eigenwilligen Stadtverordnetenversammlung ergaben. Die Entgegensetzung von Reichsspitze und Berliner Stadtregierung wurde deutlich, als der Kaiser wiederholt liberalen Oberbürgermeistern im Anschluß an ihre Wahl

${ }^{27}$ An die Stelle des Regierungspräsidenten trat in Berlin der Polizeipräsident, der seinerseits direkt dem preußischen Ministerium des Innern unterstand und also neben der Polizeigewalt zugleich auch die Befugnisse eines Regierungspräsidenten innehatte. Vgl. HEFFTER, Selbstverwaltung, S. 621; DIETRICH, Verfassung, S. 217.

28 Die Stadtverordnetenversammlung tagte ab 1822 im Cöllnischen Rathaus an der Breiten Straße/Gertraudenstraße, ab 1870 im Roten Rathaus an der damaligen Königstraße; ab 1847 waren die Sitzungen öffentlich. In Berlin wählten $2 \%$ der Wahlberechtigten in der ersten, $10 \%$ in der zweiten und alle übrigen in der dritten Klasse. Vgl. Hans J. REICHHARDT, Die Entstehung der Verfassung von Berlin. Eine Dokumentation, Bd. 1, Berlin 1990, S. 6; HEFFTER, Selbstverwaltung, S. 615; Gerhard KUTZSCH, Der Staat und die Stadt Berlin, in: Der Bär von Berlin 17 (1968) S. 7-21, hier S. 17f.

Vgl. HARDTWIG, Bürgertum, S. 273.

30 Vgl. DETRICH, Verfassung, S. 235; REICHHARDT, Entstehung, S. 9. Die Stadtverordneten wurden ihrer Kompetenz nach strikt auf den Bereich der "Gemeinde-Angelegenheiten" festgelegt, sie mußten den Magistrat für alle Beschlüsse und die Bildung von Deputationen um Zustimmung ersuchen und konnten per königlicher Verordnung als Versammlung aufgelöst werden.

31 Vgl. DIETRICH, Verfassung, S. 254.

32 Das seit der Verfassungsrevision 1854 bestehende preußische Herrenhaus als vom Monarchen bestimmte Versammlung und das Abgeordnetenhaus hatten keine Kompetenzen beim Denkmalerrichtungsverfahren. 
die Bestätigung im Amt versagte ${ }^{33}$. Ungeachtet derartiger Eklats und wiederholter Klagen Bismarcks über den mißliebigen »Fortschrittring« in Berlin, die Berliner Liberalen und Sozialdemokraten im Reichstag, hat sich die Kapitale zu einem zentralen Rückhalt bürgerlicher-liberale Kräfte zu entwickeln vermocht $^{34}$ und ist in politischer Hinsicht durchaus als "Metropole der Opposition $\aleph^{35}$ in Erscheinung getreten ${ }^{36}$.

Der zentralen Rolle des Monarchen im Entscheidungsverfahren tat in Berlin auch ein privater Entstehungskontext von Denkmälern keinen Abbruch. Bereits der Umstand, daß ein städtisches Komitee Friedrich Wilhelm IV. direkt seine Konstitutierung und sein Vorhaben mitteilte, eine Statue für König Friedrich Wilhelm III. im Tiergarten zu errichten ${ }^{37}$, ließ keinen Zweifel an der vollständigen obrigkeitlichen Kontrolle des gesamten Verfahrens. In der Tat setzten die Stifter den Monarchen eigens von der Neukonzeption des Bildprogramms in Kenntnis ${ }^{38}$ und ließen sich den bereits zugesagten Aufstellungsort ${ }^{39}$ und die Inschrift noch einmal bestätigen ${ }^{40}$. Von massiver monarchischer Dominanz zeugte einmal mehr die langwierige Genese des schließlich 1851 Unter den Linden eingeweihten Friedrich II.-Denkmals ${ }^{41}$. Als sich 1829 die kurmärkische Ständeversammlung mit der Bitte an Friedrich Wilhelm III. wandte, Friedrich dem Großen ein Denkmal errichten und hierfür Sammlungen durchführen zu dürfen ${ }^{42}$, wurde sie mit dem Hinweis auf eine bereits laufende Stiftungsinitiative des Monarchen abgewiesen ${ }^{43}$. Erst unter dem Eindruck des formellen Antrags und in dem Bestreben, sich gerade im Blick auf die Stiftung

33 Vgl. SCHREIBER, Das Berlinische Rathaus, S. 91-95.

34 Vgl. Wolfgang J. MOMMSEN, Kaisermacht und Bürgerstolz. Berlin als Hauptstadt des Kaiserreiches, in: Uwe ScHULTZ (Hg.), Die Hauptstädte der Deutschen: von der Kaiserpfalz in Aachen zum Regierungssitz Berlin, München 1993, S. 181-193, hier S. 190-192; Vgl. Hans J. REICHHARDT, Wahlen in Berlin 1809-1967. Ein Rückblick auf 160 Jahre Kommunalpolitik, Berlin 1970 (Berliner Forum, 7/70), hier S. 8-15 und SEIER, Berlin, S. 43.

35 Michael ERBE, Berlin als Brennpunkt der Politik, in: Wolfgang RTBBE (Hg.), Geschichte Berlins Bd. 2: Von der Märzrevolution bis zur Gegenwart, München 1987, S. 755-777, hier S. 755.

${ }^{36}$ Vgl. GaLl, Berlin als Zentrum, S. 236.

37 Vgl. Schreiben des Komitees an den König vom 8. August 1841, GStA I. HA Rep. 89 Nr. 20914, Bd. 1, Bl. 24; Plazet des Königs am 28. August 1841 an das Komitee, ibid. Bl. 27.

38 Vgl. Schreiben des Komitees an den König vom 15. Juli 1845, GStA PK ibid. Bl. $55 f$.

${ }^{39}$ Vgl. Schreiben des Komitees an den König vom 19. Juni 1849, ibid. Bl. 69.

40 Vgl. Schreiben des Komitees an den König am 7. August 1849, ibid. Bl. 77.

41 Zur langen Vorgeschichte des Monuments vgl. Jutta VON SIMSON, Geschichte des Denkmals. Die plastischen Entwürfe, in: DIES., Das Berliner Denkmal für Friedrich den GroBen. Die Entwürfe als Spiegelung des preußischen Selbstverständnisses, Berlin 1976, S. 7-26.

$42 \mathrm{Vgl}$. Abschrift der Immediatvorstellung der Deputation des Provincial-Landtages der Mark Brandenburg und des Markgrafthums Niederlausitz vom 24. Januar 1829, GStA PK I. HA Rep. 93 B Nr. 2355, Bl. 3.

${ }^{43} \mathrm{Vgl}$. Zum Landtagsbescheid für die Brandenburgischen Stände, ibid. Bl. 17. 
öffentlicher Monarchendenkmäler nicht des dynastischen Handlungsmonopols zu begeben, intensivierte der König sein Engagement. Er ließ eine Sachverständigenkommission bilden, deren Modellentwürfen er freilich ebensooft widersprach, wie dies zuvor bereits gegenüber einzelnen Künstlern geschehen war. Sein Beharren auf eigenen Formmodellen, seine permanente Kritik und vielfachen Änderungswünsche an vorgelegten Entwürfen trugen erheblich zur Langwierigkeit des Verfahrens bei. Erst um 1839 sorgte sein Plazet zur Denkmalform der Reiterstatue für eine Beschleunigung, die nach seinem Tod 1840 und nach der Weiterführung des Projekts unter Friedrich Wilhelm IV. anhielt. Das gesamte Denkmalunterfangen unterlag der monarchischen Direktive und blieb organisatorisch immer ein staatliches Projekt ${ }^{44}$.

Über die Zäsur von 1871 hinaus blieb die monarchische Dominanz in den Denkmalerrichtungsverfahren ungebrochen. Dies galt zunächst für alle Monarchendenkmäler. So ging die Initiative zur Errichtung eines Denkmals für Friedrich Wilhelm III. zunächst von Friedrich Wilhelm IV. aus und griff 1858 der Prinzregent und spätere Kaiser Wilhelm I. den Plan wieder auf ${ }^{45}$. Auf seine Anregung hin trat eine Beratungskommission zusammen, der u.a. der Minister der geistlichen, Unterrichts- und Medizinalangelegenheiten von BethmannHollweg und der »Historiograph des Deutschen Staates« Leopold von Ranke angehörten ${ }^{46}$. Der Monarch genehmigte die Personal $-^{47}$ und Standortvorschlä$\mathrm{ge}^{48}$ und entschied 1861 über das auszuführende Modell ${ }^{49}$, das er mit Modifikationen bewilligt hatte ${ }^{50}$. Per Erlaß wurde die Grundsteinlegung auf den 17. März 1863 gelegt, an dem sich Friedrich Wilhelms III. »Aufruf an mein

44 Vgl. unter zahlreichen Quellen hier nur Kurt MERCKLE, Das Denkmal König Friedrichs des Großen in Berlin. Aktenmäßige Geschichte und Beschreibung des Monuments, Berlin 1891; Andreas SOMMER, Gedenkbuch, enthaltend: die Geschichte und Beschreibung des Friedrich-Denkmals in Berlin, so wie die Darstellung der Grundsteinlegung am 1. Juni 1840 und der Enthüllung desselben am 31. Mai 1851, Berlin 1852; August KOPISCH, Beschreibung und Erklärung des Denkmales Friedrichs des Zweiten in Berlin, Berlin 1851; [An.,] Die Friedrichsfeier in Berlin am 31. Mai 1851. Ein Gedenkbuch für alle Preußen, Berlin 1851, S. 27-38; F. KOHLHEIM, Das Denkmal Friedrichs des Großen in Berlin. Beschrieben und mit Gedichten aus älterer und neuerer Zeit versehen, Berlin 1851, S. 2-12; Berlinische Nachrichten, 31. Mai 1851, S. 1-3.

45 Vgl. Fürst Hohenzollern-Sigmaringen und Bethmann-Hollweg an den Prinzregenten am 17. Januar 1859, GStA PK I. HA Rep. 89 Nr. 20916, Bl. 16-17. In diesem Stadium war noch an die Verbindung mit einem Denkmal für den preußischen Reformer Freiherm vom Stein gedacht.

46 Vgl. ibid. Bl. 17; Memorandum vom 23. April 1863, GStA PK ibid. Bl, 120-123, hier B1. 120.

47 Vgl. der Regent an von Hohenzollern-Sigmaringen, 26. Januar 1859, ibid. Bl. 18.

48 Vgl. Mitteilung des Prinzregenten an dens., 18. Februar 1860, GStA PK I. HA Rep. 151 I C Nr. 8321, Bl. 9 .

49 Vgl. Wilhelm I. an dens. am 29. April 1861, GStA PK Rep. 89 Nr. 20916, Bl. 14.

so Vgl. Wilhelm I. an Staatsminister von Auerswald, 8. Februar 1862, GStA PK I. HA Rep. 151 I C Nr. 8321, BI. 10. 
Volk« zum fünfzigsten Mal jährte, und der konservative Minister der geistlichen Angelegenheiten Heinrich von Mühler beauftragt, das Zeremoniell zusammen mit dem preußischen Ministerpräsidenten vorzubereiten ${ }^{51}$. Ebenso unterlag das Einweihungsfest ganz den Anweisungen Wilhelms I. $^{52}$.

$\mathrm{Zu}$ den wohl rigidesten Fällen monarchischer Intervention gehörte aber die Einmischung Wilhelms II. in ein von Reichstagsmitgliedern auf den Weg gebrachtes Projekt zugunsten eines Monuments für Wilhelm I., das später 1897 auf der Schloßfreiheit eingeweiht werden sollte. Über Standorte ${ }^{53}$ und Wettbewerbsverfahren ${ }^{54}$ hatte man sich längst verständigt ${ }^{55}$ und die 148 eingereichten Entwürfe waren längst öffentlich ausgestellt ${ }^{56}$, als der Kaiser den Wettbewerb präjudizierte, indem er am Votum der Jury vorbei den Entwurf des Bildhauers Begas demonstrativ belobigte und die Schloßfreiheit offen als Standort favorisierte $^{57}$, obgleich das Preisgericht sich mit seinen Prämierungen auf ein für den Königsplatz vorgesehenes architektonisches Projekt festgelegt hatte ${ }^{58}$. Auch deutliches Befremden in der Presse ${ }^{59}$ konnte die Monopolisierung des Entscheidungsablaufs durch Wilhelm II. nicht verhindern ${ }^{60}$. Mit der mehrheitlich

51 Vgl. von Mühler an Finanzminister von Bodelschwingh, 19. Februar 1863, GStA PK I. HA Rep. 151 I C Nr. 8321, B1. 40.

52 Gedacht war zunächst an den 3 . August 1870 als 500. Jubiläum des Geburtstags Friedrichs. Vgl. Wilhlem I. an von Mühler vom 20. Mai 1869, GStA PK, ibid. Bl. 95. Unter dem Eindruck des Krieges fand die Einweihung - freilich erneut nach monarchischer Regieanweisung - erst 1871 statt.

53 Vgl. Sitzung des Reichstags am 11. Dezember 1888, in: Stenographische Berichte über die Verhandlungen des Reichstages [SBVRT], VII. Legislaturperiode, IV. Session 1888/89, Bd. 1, Berlin 1889, S. 233-234, hier S. 233; Sitzung des Reichstages vom 14. Dezember 1888, in: Ibid. S. 302.

54 Vgl. Bedingungen der Preisbewerbung, ibid. S. 4f.; von Boetticher an den Präsidenten des Reichstages von Levetzow am 30. Januar 1889, ibid. $\mathrm{N}^{\circ} 90$ [up].

55 Vgl. Sitzung des Reichstags am 30. März 1889, in: SBVRT, 7. Legislaturperiode, 4. Session 1888/89, S. 1155.

${ }^{56} \mathrm{Vgl}$. Bericht des Direktors des Reichsamts des Inneren an von Lucanus am 4. September 1889, GStA PK, I. HA Rep. 89 Nr. 20933, Bl. 47.

57 Vgl. v.a. Vossische Zeitung, 14. Oktober 1889, LAB A Rep. 000-02-01 Nr. 1627, Bl. 60 und 61 .

58 Vgl. Deutscher Reichsanzeiger, 4. Oktober 1889, LAB ibid. Bl. 57. Zum Wettbwerb vgl. H. BLANKENSTEIN, Über die Ergebnisse der Wettbewerbung zum National-Denkmal für Kaiser Wilhelm. Vortrag gehalten im Architektenverein zu Berlin am 14. Oktober 1889, Berlin 1889; HossfeLD, Die Preisbewerbung um das National-Denkmal für Kaiser Wilhelm I. in Berlin, Berlin 1889; Georg Voss, Die Entscheidung über die Entwürfe zum Nationaldenkmal für Kaiser Wilhelm. Dem Deutschen Reichstage als Denkschrift überreicht, Berlin ${ }^{2}$ 1889; BECHDOLT, Zur Kaiser-Denkmalfrage in Berlin, o. O. o. J. [gedruckt in: GStA PK I. HA Rep. 77 Tit. 151 Nr. 106 Adh.1].

59 Vgl. Berliner Tageblatt, 14. Februar 1890, LAB ibid. BI. 85

60 Vgl. Drucksache des Bundesraths $N^{\circ}$ 61, Session von 1890. Antrag, in: Drucksachen zu den Verhandlungen des Bunderaths des Deutschen Reichs, Jahrgang 1890, Bd. 1, Berlin 1890, S. 2-6, hier S. 3 und Reichstag. Aktenstück Nr. 54 (Nationaldenkmal für Kaiser 
erteilten Zustimmung zur Kompetenzübertragung an Wilhelm II. begab sich der Reichstag schließlich definitiv jeder gestalterischen Rolle. Standortwahl, Wettbewerbsverfahren und schließlich die Auswahl des Entwurfs blieben ganz dem Monarchen überlassen ${ }^{61}$.

Darüber hinaus verteidigten die preußischen Regenten wiederholt ihr monarchisches Darstellungs- und Deutungsmonopol für Monarchendenkmäler gegenüber bürgerlichen Organisatorengruppen. So wurde der Plan einer Gruppe von Stadtverordneten, ein Friedrich III.-Monument auf städtische Kosten zu errichten $^{62}$, sofort vom Monarchen kassiert ${ }^{63}$. Ebenso machte Wilhelm I. gegenüber bürgerlichen Vereinen, die eine Denkmalehrung für die preußische Königin Luise planten ${ }^{64}$, geltend, daß »die Institution zu einem öffentlichen Denkmal, welches in der Hauptstadt des Landes einem Mitgliede der Königlichen Familie gewidmet werden soll, nur allein von der Allerhöchsten Person ausgehen « dürfe ${ }^{65}$. Daß der symbolische Gestaltungswille sich unterdessen durchaus auch auf anderes, bevorzugt militärisches Personal erstreckte, dokumentierte etwa die 1880 von Wilhelm I. abgeschlossene Initiative zur Errichtung einer Statue für Generalfeldmarschall Friedrich von Wrangel ${ }^{66}$.

Um ihr Handlungsmonopol zu wahren, schalteten sich die Monarchen auch in bereits laufende Verfahren ein. Als man Friedrich Wilhelm IV. um Genehmigung der Statue für den preußischen Reformer Freiherr vom Stein ersuchte, konnte er sich eine Denkmalerrichtung nicht anders als auf Staatskosten vorstellen $^{67}$. Die vom Zentralverein zur Errichtung des Stein-Denkmals bereits

Wilhelm I.), in: SBVRT, 8. Legislaturperiode, 1. Session 1890/91, 1. Anlageband, Berlin 1890, S. 543-545.

61 Vgl. Bericht von Boettichers an den Kaiser, 2. Juli 1890, GStA PK ibid. Bl. 60-65, hier Bl. 60,63 und 65 .

62 Vgl. Auszug aus dem SBSV am 27. September 1888, LAB A Rep. 000-02-01 Nr. 1627, Bl. 7-8 und Forckenbeck am 8. Mai 1889 an den Kaiser, GStA PK I. HA Rep. 89 Nr. 20939, Bl. 3.

${ }_{63}$ Vgl. Wilhelm II. an den Magistrat von Berlin, 26. Mai 1890, GStA PK ibid. BI. 6.

64 Vgl. Statuten des Vereins, 26. November 1875, GStA PK I. HA Rep. 89 Nr. 20903, B1. 123.

65 Schreiben Wilhelms I. an den Minister der geistlichen Angelegenheiten, November 1875, GStA PK ibid. Bl. 117. Schließlich lag im März 1876 aber doch seine ausdrückliche Bewilligung des Denkmals vor. Vgl. Wilhelm I. an Finanzminister Camphausen, 16. März 1878, GStA PK ibid. Bl. 147. Vgl. ähnlich auch die Involvienung Wilhelms II. 1895 in die Denkmalinitiaitive zugunsten der Kaiserin Augusta; dazu z.B. der Brief von Lucanus an den Vorsitzenden des Denkmalkomitees Stryck vom 13. Oktober 1895, LAB A Rep. 00002-01 Nr. 2381 [up]

${ }^{66}$ Vgl. Abschrift der Kabinettsordre vom 15. August 1876, GStA PK I. HA Rep. 89 Nr. 20836, BI. 28; Schreiben Wilhelms I. an den Finanz- und den Kultusminister, 23. Januar 1878, GStA PK ibid. Bl. 30 und Anordnung Wilhelms I. vom 19. Mai 1880, GStA PK ibid. Bl. 61.

67 Vgl. Prinz von Preußen an den Ministerpräsidenten, 18. August 1858, GStA PK I. HA Rep. 151 I C Nr. 8321, Bl. 2. Vgl. zur Initiative ausführlicher Teil 2, Kapitel IV.2.2. 
gesammelten Gelder war er durchaus zu nutzen bereit, untersagte aber die Ausschreibung einer öffentlichen Konkurrenz ${ }^{68}$. Als der Zentralverein einen Subskriptionsaufruf lancierte ${ }^{69}$, kam ihm der Monarch zuvor, indem er nun seinerseits die Stein-Statue in Auftrag gab ${ }^{70}$.

Zum Beharren auf monarchischen Kompetenzen zählte weiterhin, daß Wilhelm I. das Denkmalareal in der Nähe des monarchischen Repräsentationszentrums um das Schloß und am Ostende der Linden zunächst nur äußerst unwillig auch für nicht-dynastische Denkmalprojekte öffnete. Eine Anfrage des Komitees zur Errichtung der beiden Humboldt-Denkmäler vor der Universität $^{71}$ wies der Monarch zunächst mit der Begründung zurück, man wolle die Stadtmitte und vor allem das unmittelbare Umfeld des Friedrich II.-Denkmals unter den Linden von weiteren Symbolfiguren freihalten ${ }^{72}$. Eine kaiserliche Genehmigung $^{73}$ folgte später überhaupt nur einschließlich neuerlicher Detailanweisungen, wonach die neuen Figuren denjenigen der Generalstandbilder vor der Neuen Wache deutlich untergeordnet bleiben sollten ${ }^{74}$. Während die Anfänge der Initiative noch im engen intentionalen Zusammenhang mit einer Welle der Humboldtverehrung standen, die sich seit den 1860er Jahren im Kontext der Neuen Ära in der Bildung von Humboldtvereinen als den Institutionen popularisierter Wissenschaftsvermittlung Bahn brach ${ }^{75}$, unterlag das Projekt so im autoritären Kaiserreich dem monarchischen Zugriff ${ }^{76}$.

Vgl. Wilhelm an Fürst zu Hohenzollern-Sigmaringen, 18. Februar 1860, GStA PK I. HA Rep. 151 I C Nr. 8321, Bl. 9.

69 Vgl. Subskriptionsaufruf des Central-Vereins zur Errichtung eines Denkmals für den Minister Freiherrn vom Stein, 12. März 1860, BLHA Rep. 2A I P Nr. 719 [up].

70 Vgl. Erlaß des Königs vom 8. Februar 1862, GStA PK I. HA Rep. 151 I C Nr. 8321, BI. 10. Vgl. auch das Schreiben des Central-Vereins an von Mühler, 28. März 1862, GStA PK I. HA Rep. 89 Nr. 20916, Bl. 63-64. Bis das Stein-Denkmal fertiggestellt war, hatte man den ursprünglichen Plan einer Statuengruppe im Lustgarten um das Denkmal Friedrich Wilhelms III., zu der auch die Stein-Statue zählen sollte, bereits wieder aufgegeben, so $\mathrm{da} B$ nun die Einzelaufstellung auf dem Dönhoffplatz anvisiert werden konnte. Vgl. National-Zeitung, 26. Oktober 1875 (M.), S. 2.

71 Vgl. Emil DU BOIS-REYMOND, Die Humboldt-Denkmäler vor der Berliner Universität. Zur Feier des Geburtstages Friedrich Wilhelm's III. in der Aula der Königlichen FriedrichWilhelms-Universität zu Berlin am 3. August 1883 gehaltene Rede, in: DERS., Friedrich II. in englischen Urtheilen. Darwin und Kopernikus. Die Humboldt-Denkmäler vor der Berliner Universität. Drei Reden, Leipzig 1884, S. 59-120, hier S. 61.

72 Vgl. Wilhelm I. an das Komitee, 27. August 1869, GStA PK I. HA Rep. 89 Nr. 20835, Bl. 196.

73 Vgl. Erklärung Wilhelms I. vom 10. April 1875, GStA PK I. HA Rep. 89 Nr. 20836, Bl. 10.

74 Vgl. Falk an den König, 25. November 1878, GStA PK ibid. Bl. 41.

75 Vgl. Andreas W. DAUM, Wissenschaftspopularisierung im 19. Jahrhundert. Bürgerliche Kultur, naturwissenschaftliche Bildung und die deutsche Öffentlichkeit, 1848-1914, München 1998, S. 138-167.

${ }^{76}$ Für die Programmatik des Denkmals sollte dieser Umstand erkennbare Folgen haben, indem die »liberale« Aneigung Humboldts durch die Initiatoren bis zum Zeitpunkt der Inau- 
Generell mußte der Monarch auch dann um Zustimmung ersucht werden, wenn das als Standort anvisierte Terrain in anderweitigem Besitz war. So mußte das Komitee zur Errichtung des Jahn-Denkmals nicht nur bereits für die Standortwahl in der Hasenheide die Zustimmung des staatlichen Unterrichtsministeriums einholen, dem das Terrain hälftig gehörte ${ }^{77}$, sondern auch den monarchischen Konsens erbitten, der knapp ein halbes Jahr später unter dem Vorbehalt erteilt wurde, daß eine gesicherte Kostendeckung nachgewiesen würde ${ }^{78}$.

Gelegentlich setzte der Monarch seine Entscheidungsvollmacht zur Obstruktion unerwünschter Projekte ein. Obwohl das Komitee, das den Linksliberalen Hermann Schulze-Delitzsch zu ehren gedachte und sich um eine Plazierung seiner Statue auf dem Alexanderplatz bewarb ${ }^{79}$, obrigkeitliche Kritik zu umgehen versuchte, indem es unterstrich, nur die "volkswirtschaftliche«, nicht aber die "politische« Rolle Schulze-Delitzschs erinnern zu wollen, genehmigte Wilhelm II. das Projekt zunächst nicht. Er ließ aber Konzessionsbereitschaft erkennen, sobald man sich seitens des Komitees zur Auswahl eines deutlich »bescheideneren Platz[es] « bereitfinden würde ${ }^{80}$. Wiederholte, aber gleichwohl devote Vorstöße des Komitees, die mit immer unscheinbareren Standortvorschlägen ${ }^{81}$ verbunden waren, mochten Wilhelm II. von der sekundären Qualität des inzwischen vorgeschlagenen Ortes überzeugt haben. Jedenfalls folgte nun nach zustimmenden Voten auch des Magistrats und des Polizeipräsidiums $^{82}$ vergleichsweise prompt die Standortgenehmigung für einen Platz im Stadtteil Köpenick ${ }^{83}$. Daß die städtischen Behörden einschließlich des Magistrats das Denkmalprojekt über alle Phasen der Standortsuche unterstützten, während sich der Kaiser erst spät zur Billigung das Plans bereitfand, zeugte zugleich von der politischen Distanz der städtischen Entscheider zum Monarchen.

guration 1883 nur noch abgeschwächt vertreten werden konnte; vgl. dazu Teil 2, Kapitel VI.2.

${ }^{77}$ Vgl. Carl EULER, Das Jahndenkmal in der Hasenhaide in Berlin. Eine ausführliche Darstellung seiner Geschichte und Beschreibung der bei seiner Enthüllung am 10. und 11. August 1872 veranstalteten Feierlichkeiten, Beilage zur Deutschen Turnerzeitung 1873-1874, Leipzig 1874, S. 7.

78 Vgl. die Antwort des Königs vom 18. April 1869, GStA PK I. HA Rep. 89 Nr. 20835, Bl. 182 und 184 .

79 Vgl. Innenminister Herffurth an den Kaiser, 23. November 1891, GStA PK I. HA Rep. 89 Nr. 20837, BI. 7; Schreiben des (freisinnigen) Bürgermeisters Forckenbeck und weiterer Komiteemitglieder an den Polizeipräsidenten vom 10. September 1891, GStA PK I. HA 93 B Nr. 2365, BI. 57.

${ }^{80}$ Vgl. Bericht an den Innenminister von 1891, GStA PK I. HA Rep. 89 Nr. 20837, Bl. 16.

${ }^{81}$ Vgl. Gesuch des Komitees an den Kaiser am 4. Dezember 1895, GStA PK ibid. Bl. 106.

${ }^{82}$ Vgl. Bescheid des Magistrats vom 19. März 1895, GStA PK I. HA Rep. 93 B Nr. 2365, BI. 104

83 Vgl. Anweisung vom 9. Dezember 1895, GStA PK I. HA Rep. 89 Nr. 20837, Bl. 108. 
Massive Obstruktion von monarchischer und ministerieller Seite prägte schließlich die Vorgänge um das verhinderte Denkmal für die Märzgefallenen. Im März 1895 veröffentlichte der Freisinnige Arbeiterverein Berlins (später Freisinniger Volksverein) eine die alten Pläne von 1848 wiederaufgreifende Resolution, derzufolge die »Kämpfer« von 1848 ein Denkmal erhalten sollten und forderte alle "Bürger « zur Subskription auf ${ }^{84}$. Der Oberpräsident der Provinz Brandenburg Heinrich von Achenbach äußerte gegenüber dem preußischen Innenminister von der Recke massive Bedenken gegen eine Beteiligung des Magistrats ${ }^{85}$. Unterdessen votierten die Stadtverordneten jetzt für die Errichtung eines "Eingangsportals« oder eines Gedenksteins auf dem Friedhof als Monument-Ersatz ${ }^{86}$. Dennoch lehnte der Magistrat im Januar 1898 nach massiver Einflußnahme des Ministerrats auf Oberbürgermeister Zelle ${ }^{87}$, die Vorlage der Stadtverordneten $a b^{88}$, deren Protest ${ }^{89}$ folgenlos verhallte. Als sie Klage gegen den Magistrat beim Oberverwaltungsgericht erhoben ${ }^{90}$, erhielt der Magistrat Recht ${ }^{91}$. Auch ein erneuter Vorstoß des Komitees der Märzgefallenen scheiterte ${ }^{92}$, so daß keines der Projekte zum Gedächtnis an die Revolutionsereignisse von 1848 zustandekam. Anders als in Paris, wo der Widerstand gegen das Denkmalprojekt für die Kommunardenopfer gebrochen werden konnte, setzte sich in Berlin die reaktionäre Obstruktion durch ${ }^{93}$.

Konflikte zwischen Kaiser und Stadverordnetenversammlung traten am Ende im Zusammenhang mit dem Rudolf Virchow-Monument auf, das 1910 eingeweiht werden konnte. Aus ihrer relativ hohen finanziellen Beteiligung am Projekt leitete die Stadtverordnetenversammlung ein Mitspracherecht bei der Konzeptionierung des Monuments ab und legte Wert darauf, daß Virchow nicht nur als Pathologe und Anthropologe, sondern auch als »Kommu-

84 Vgl. Heinz KRIEGER, Die Kämpfe um ein Märzdenkmal (1848-1898). Ein Beitrag zur Kulturgeschichte. Im Auftrag des Denkmal-Comités von 1896, Berlin 1899, S. 16.

${ }^{85} \mathrm{Vgl}$. Schreiben des Oberpräsidenten der Provinz Brandenburg an den Innenminister, 10. November 1897, GStA PK I. HA Rep. 77 Tit. 151 Nr. 109, Bl. 7.

${ }^{86} \mathrm{Vgl}$. SBSV am 29. Dezember 1897, LAB A Rep. 001-02 Nr. 269, Bl. 84-87, hier Bl. 87.

87 Vgl. Geheime Abschrift des Sitzungsprotokolls des königlichen Staatsministeriums, 18. Dezember 1897, GStA PK I. HA Rep. 77 Tit. 151 Nr. 109, Bl. 27; Geheime Abschrift des Sitzungsprotokolls des Königlichen Staatsministeriums vom 30. Dezember 1897, GStA PK ibid. BI. 40.

${ }^{88}$ Vgl. Vorlage Nr. 5 vom 25. Dezember 1898, LAB A Rep. 001-02 Nr. 269, Bl. 92.

${ }^{89}$ Vgl. SBSV am 3. Februar 1898, LAB A Rep. 001-02 Nr. 269, Bl. 112-113.

90 Vgl. Abschrift. Klage der Stadtverordnetenversammlung, GStA PK Rep. 77 ibid. Bl. 87 92.

91 Vgl. KRIEGER, Kämpfe, S. 39.

92 Schreiben des Schriftfuihrers des Märzgefallenenkomitees Krieger an die Stadtverordnetenversammlung, 4. Februar 1900, LAB A Rep. 001-02 Nr. 269, Bl. 234.

93 Ausfuihrlich zum Vergleich der beiden Projekte, der noch einmal Verfahrensfragen berücksichtigt, Kapitel I.1.1.1., I.2 und I.4 im zweiten Teil. 
nalpolitiker und Politiker« erkennbar sein müsse ${ }^{94}$. In der Tat war sie auch im Preisgericht vertreten, das über die im Rahmen eines Wettbewerbs eingereichten Entwürfe zu entscheiden hatte ${ }^{95}$. Der ausgewählte Entwurf ${ }^{96}$ zog aus ästhetischen Gründen massive Kritik bürgerlicher Vereine, der medizinischen Gesellschaft $^{97}$ und des Vereins für innere Medizin ${ }^{98}$ auf sich, konnte aber durch Korrekturen des Künstlers aufgefangen werden ${ }^{99}$, bis sich der Kaiser entschloß, die Genehmigung für die Denkmalerrichtung im April 1908 zu verweigern $^{100}$. Auf einer Photographie machte Wilhelm II. akribisch mit Rotstift kenntlich, welche Stellen am Denkmal er korrigiert zu sehen wünschte ${ }^{101}$ und erteilte sein Plazet erst ${ }^{102}$, nachdem seine Beanstandungen berücksichtigt worden waren. Nicht nur die linke Münchner Post interpretierte den Vorfall als eminent politischen Akt und gezielte Obstruktion des Monarchen gegen ein öffentliches Denkmal für einen »Freisinnigen ${ }^{103}$. Freilich gehörte das Blatt damit zu den wenigen Organen, die die Instrumentalisierung des ästhetischen Arguments durch den Monarchen ausdrücklich nahelegten. Dominante Initiativen, gelegentliche Interventionen und sporadische Obstruktion ließen die preußischen Monarchen damit als zentrale Entscheider im Verfahren öffentlicher Denkmalerrichtungen in Berlin erscheinen, ohne daß selbst mißliebige Symbolsetzungen immer verhindert worden wären ${ }^{104}$.

Vgl. Auszug aus dem SBSV vom 7. September 1905, LAB A Rep. 000-02-01 Nr. 1636, BI. 55.

95 Vgl. Gemeindeblatt vom 17. Dezember 1905, LAB A Rep. 000-02-01 Nr. 1636, Bl. 57.

96 Vgl. Gemeindeblatt, 13. Mai 1906, LAB ibid. Bl. 62.

${ }^{7}$ Zur medizinischen Gesellschaft vgl. Constantin GOSCHLER, Wissenschaftliche "Vereinsmenschen . Wissenschaftliche Vereine in Berlin im Spannungsfeld von Wissenschaft und Offentlichkeit, 1870-1900, in: DERS. (Hg.), Wissenschaft und Öffentlichkeit in Berlin, 1870-1930, Stuttgart 2000, S. 31-63.

98 Vgl. stellvertretend für sie das ablehnende Gutachten eines Dr. D. Sarason, Zur Frage des Virchow-Denkmals, aus: Berliner Aerzte-Correspondenz 22 (1906), GStA PK I. HA Rep. 93 B Nr. 2366, Bl. 90.

99 Vgl. Frankfurter Zeitung, 14. April 1908, GStA PK ibid. Bl. 68; Kunstchronik 18 $(1906 / 07)$ Sp. 392.

${ }^{100}$ Vgl. Vossische Zeitung, 14. April 1908, LAB A Rep. 000-02-01 Nr. 1636, Bl. 25.

${ }^{101}$ Mitteilung an den Minister für öffentliche Arbeiten Breitenbach und Innenminister Moltke, 17. März 1908, GStA PK I. HA Rep. 93 B Nr. 2366, Bl. 61.

${ }^{102} \mathrm{Vgl}$. der Vorsitzende des Virchow-Komitees an Innenminister von Moltke, 20. Januar 1909, GStA PK Rep. 77 Tit. 151 Nr. 15 Fasz. 51, Bl. 6.

${ }^{103}$ Vgl. Münchner Post, 16. April 1908, GStA PK Rep. 93 B Nr. 2366, Bl . 79.

${ }^{104}$ Vgl. dazu auch [An.,] Die Krone und die Reichshauptstadt. Allgemeinpolitische Betrachtungen und Erörterungen der Konflikte zwischen der Krone und der Stadt Berlin. Von einem Berliner, Berlin 1902; Paul SEIDEL, Der Kaiser und die Kunst, Berlin 1907. 


\subsection{London}

Die Zuständigkeit lokaler oder staatlicher Gremien im Rahmen öffentlicher Denkmalpolitik ergab sich auch in London zunächst aus dem Grundstücksbesitz, der wiederum die komplexe, inkohärente Verwaltungsstruktur des metropolitanen Terrains widerspiegelte. Bodenrechte in Kronbesitz involvierten automatisch Her Majesty's Office of Works, städtische Aufstellungsorte konnten eine Zuständigkeit des 1855 gegründeten und bis zum Ende seines Bestehens etwa $25 \%$ des städtischen Bodens kontrollierenden ${ }^{105}$ Metropolitan Board of Works [MBW] und ab 1888 seines Nachfolgers, des London County Council [LCC], nach sich ziehen. Vor wie nach diesem Zeitpunkt waren aber auch die parallel weiter existierenden Parishes oder Vestries weisungsbefugt, darunter auch die City of London Corporation als historisch älteste und profilierteste administrative Einheit. In der überwiegenden Zahl der Fälle bedurften Denkmalerrichtungen in London der Zustimmung und Kontrolle durch das Office of Works, das seit dem frühen 19. Jahrhundert und mit nach der Jahrhundertmitte ausgedehnter Reichweite für den Bau und Erhalt öffentlicher Gebäude zuständig war, sofern sie entweder aus dem königlichen Haushalt oder aus parlamentarischen Geldern finanziert worden waren, daneben für die Restauration königlicher Paläste und den Erhalt öffentlicher Plätze, Parks und Straßen ${ }^{106}$. Seit 1851 präsidierte dem Office ein königlich ernannter und im Kabinett vertretener First Commissioner of Works and Public Buildings ${ }^{107}$, dem der personelle Zuschnitt des Office auch hinsichtlich öffentlicher Denkmalbauten innerhalb des städtischen Kerngebiets ("within the metropolis«) eine zentrale Entscheidungsposition verlieh.

Mit öffentlichen Denkmalerrichtungen auf städtischem Grund außerhalb des Metropolitan District war hingegen nach dem Office of Works am häufigsten der seit 1855 bestehende MBW befaßt, der sonst vor allem Aufsichts- und Koordinationsfunktionen hatte ${ }^{108}$. Fragen der Denkmalerrichtung kamen in den Plenumsversammlungen des MBW (Full Board) lediglich an untergeordneter Stelle zur Sprache und wurden selten von hier aus an Subkomittees zur Weiterbehandlung verwiesen ${ }^{109}$. Nach 1888 gingen alle Kompetenzen und Ver-

${ }^{105}$ Vgl. BRIGGS, Victorian Cities, S. 323.

${ }^{106}$ Vgl. PRO 116/1/2 Office of Works 1660 to 1832, in: Public Record Office [PRO] Guide, London 1997 [up]. Das Office of Works fusionierte 1832 vorübergehend mit dem Office of Woods, Forests and Land Revenues unter der Leitung von 3 Commissioners of Woods, Forests, Land Revenues, Works and Buildings, von denen einer zugleich Mitglied des House of Commons war.

${ }^{107}$ Vgl. PRO 116/1/4 Office of Works 1851 to 1940 , in: PRO Guide [up].

${ }^{108}$ Vgl. MBW Index, London Metropolitan Archive [LMA, up].

${ }^{109}$ Der MBW bestand aus 45, jedes Jahr zu einem Drittel durch indirekte Wahl bestimmten Mitgliedern. Vgl. DAvIs, Reforming London, S. 10-20. 3 der Mitglieder des MBW wurden dabei vom Mayor und der Corporation of the City of London bestellt, die übrigen von 
pflichtungen des Boards einschließlich seiner Zuständigkeit für die Genehmigung öffentlicher Denkmalerrichtungen an den lange von einer progressiven Allianz aus Liberalen und Labour bestimmten LCC über, dessen 188 Mitglieder jetzt in Direktwahl durch die qua Mindeststeuersatz wahlberechtigte männliche Bevölkerung bestimmt wurden ${ }^{110}$. Einen erkennbaren Politisierungsschub hat dies allerdings im Blick auf die Denkmalsetzungen nicht gezeitigt. $\mathrm{Daß}$ städtische Aufstellungsorte für Denkmäler dennoch außerhalb der Zuständigkeit des MBW wie des LCC liegen konnten, resultierte aus dem Umstand, daß der parochiale Föderalismus ${ }^{111}$ und also die Weiterexistenz einer verwirrenden Vielzahl von »vestries«, »district boards« und anderer lokaler Institutionen einschließlich bestehender Sonderrechte an Bodenbesitz bestehen blieb. Denkmalpolitisch wirkte sich dies am ehesten so aus, daß zusätzlich zu den genannten Gremien auch die City und ihre Corporation als bodenbesitzende Autoritäten auftraten ${ }^{112}$.

Auf Anregung des Office of Works und des $\mathrm{MBW}^{113}$ verfügte 1854 ein Gesetz, daß alle dort aufgelisteten "public statues" dem Office of Works unterstellt würden, sofern sie sich auf Straßen und Plätzen im bereits 1830 definierten "Metropolitan Police District « befanden ${ }^{114}$. Die Commissioners wurden darüber hinaus beauftragt, weitere öffentliche Denkmalerrichtungen innerhalb des Terrains zu kontrollieren und gegebenenfalls Restaurierungsarbeiten vornehmen zu lassen ${ }^{115}$. Für alle nicht im Gesetz erwähnten Denkmäler galt, daß ihre Initiatoren oder Besitzer deren Transfer in die Obhut der Commissioners schriftlich beantragen konnten ${ }^{116}$. Das Office of Works blieb dabei seiner-

den 39, später 41 Vestry und District Boards, darunter der Corporation of the City of London, in indirekter Wahl bestimmt. Metropolitan Board of Works, Index, LMA, und Francis SHEPPARD, The crisis of London's Government, in: David OWEN, The Government of Victorian London 1855-1889. The Metropolitan Board of Works, the Vestries and the City Corporation, hg. v. Roy MACLEOD, Cambridge, Mass. und London 1982, S. 23-46, hier S. 37; Stephen INWOOD, A history of London, Basingstoke und Oxford 2000, S. 432443.

${ }^{110}$ Vgl. BRIGGS, Victorian Cities, S. 325 und 331; DAVIS, Reforming, S. 20f.; LMA Information Leaflet $n^{\circ} 21$ Electoral registers at LMA, S. 3.

${ }^{11}$ Vgl. P. J. WALlER, Town, city, and nation. England 1850-1914, Oxford 1983, '²991, S. $62 \mathrm{f}$.

${ }^{112}$ Vgl. CLRO Information Sheet 8, The Court of Common Council und CLRO Information Sheet 17, Sources on Lord Mayors of London.

${ }^{113}$ Vgl. John GARDINER, London and Edinburgh. Public Statues, November 1853, PRO Work 20/233 [up].

$114 \mathrm{Vgl}$. Anno decimo septimo \& decimo octavo $\left[17^{\circ} \& 18^{\circ}\right]$ Victoriae Reginae Chapter 33. An act to place Public Statues within the Metropolitan Police District under the Control of the Commissioners of Her Majesty's Works and Public Buildings, 10. Juli 1954, PRO Work 20/56 [up], und die Definition des »Metropolitan Police District« in 10 George IV. c. 44 , PRO Work 20/223 [up].

115 Vgl. 17 \& 18 Vic. c. 33.

${ }^{116}$ Vgl. ibid. 
seits an das Votum des Finanzministeriums (Treasury) gebunden, dessen Plazet $\mathrm{zu}$ Denkmalerrichtungen oder -transfers schriftlich vorliegen mußte ${ }^{117}$ Faktisch galt damit also auch eine Art nachholende Vetoposition des Office of Works für diejenigen Denkmäler, die noch ohne seine Mitsprache zustandegekommen waren.

Nicht anders als in Paris und Berlin spielten sich für das Verfahren der Denkmalplazierungen gängige Muster ein. In der Regel gehörte es bereits zu den Planungen der Denkmalkomitees, einen Modellentwurf, einen ausführenden Künstler sowie einen Standort zu wählen und diese Vorschläge den zuständigen Gremien, meist dem Office of Works, zur Genehmigung zu unterbreiten. $\mathrm{DaB}$ die Kooperation mit dem Office Reglementierungen nach sich zog, wurde u.a. im Zusammenhang mit dem Denkmal für den Militärarzt McGrigor deutlich, als das Office dem Wunsch des Komitees nach einer prominenten Plazierung der Statue auf dem Trafalgar Square ${ }^{118}$ nicht entsprach ${ }^{119}$ und statt dessen mehrere Alternativorte ins Gespräch brachte ${ }^{120}$, bis sich das Komitee den Vorgaben am Ende beugte. Generell selten blieben dabei Initiativen, die in administrativer Hinsicht unterhalb der City-Ebene zustandekamen, wie dies etwa für das aus den Reihen des Boroughs von St. Pancras heraus betriebenen Denkmal zugunsten des Mitbegründers der Anti Corn Law-League Richard Cobden galt ${ }^{121}$.

Abweichungen von der Verfahrensnorm traten am ehesten in Verbindung mit Monumenten für besonders renommiertes Personal auf. Einen ungewöhnlichen Verlauf nahm das langwierige Verfahren zur Errichtung des NelsonDenkmals auf dem Trafalgar Square. Das im Rahmen eines öffentlichen Wett-

${ }^{117}$ Vgl. ibid. Bis zu diesem Zeitpunkt unterstanden dem Kontrollgesetz außer mehreren Monarchendenkmälern nur eine Statue für George Canning auf Parliament Square, die NelsonSäule auf Trafalgar Square, die Wellington Statuen an Hyde Park Corner und am Tower Green sowie ein Denkmal für den Duke of Kent am Portland Place. In den folgenden Jahren wurde der überwiegende Teil der öffentlichen Denkmäler nicht nur dem Gesetz gemä $\beta$ mit dem Office of Works abgestimmt, sondern ihm nach der Errichtung auch übertragen. Vgl. u. a. Public Statues, \& c. (London). Return to an order of the Honourable The House of Commons of the Public Statues or Public Monuments in London belonging to the Nation, in: HoC PP Session 1862, Paper N ${ }^{\circ}$ 366, Bd. 30, S. 593; Public Statues. Return (...) of the Public Statues and Public Monuments in London, in: HoC PP Session 1867-8, Paper $\mathrm{N}^{\circ} 480$, Bd. 55, S. 357; Statues in charge of the Commissioners of Works under Act 17 and 18 Vic. c. 33 vom September 1911, PRO Work 20/21 [up].

${ }^{118} \mathrm{Vgl}$. Schreiben des Komitees an das Office of Works am 25. Januar 1861, PRO Work $20 / 29$.

${ }^{119} \mathrm{Vgl}$. John Wyatt vom Komitee an Alfred Austin am 30. Januar 1861, PRO ibid.

${ }^{120}$ Vgl. Austin an Wyatt am 11. März 1861, PRO ibid.

${ }^{121}$ Vgl. The Daily Telegraph, 29. Juni 1868, S. 8. Sofern jeder Hinweis auf eine spezifische Bindung Cobdens an den Borough fehlt, wird in den Initiatoren eine kleine Gruppe privater und politischer Sympathisanten zu sehen sein. Vgl. auch Jean Scott ROGERS, How Cobden came to Camden Town, in: Camden History Review 9 (1981) S. 20-23. Vgl. The Daily Telegraph, 29. Juni 1868, S. 8. 
bewerbs $^{122}$ ausgewählte Modell des Architekten William Railton für eine Säulenkonstruktion stieß hier ebenso auf heftige Kritik wie das Abstimmungsverfahren im Komite ${ }^{123}$. Schließlich beschwichtigte erst ein paritätisch aus Whigs und Tories konstituiertes Select Committee die Diskussion ${ }^{124}$, indem es regelrechte Verhöre der Beteiligten durchführte ${ }^{125}$. Weniger politisch als vielmehr ästhetisch-formal und verfahrenstechnisch motivierte Einwände sorgten hier für erhebliche Irritationen und eine beträchtliche Verlängerung des Verfahrens.

Ähnliche Argumente prägten die Initiative für das Wellington-Denkmal, das 1846 auf den Triumphbogen am Hyde Park Corner zu stehen kam. Auch hier waren Konzeption und Positionierung des Monuments umstritten. Das Komitee einigte sich zwar früh auf eine Reiterstatue und visierte den Triumphbogen als Standort an ${ }^{126}$, während zugleich Premier Lord William Melbourne ${ }^{127}$ rasch ein Plazet Queen Victorias erhielt ${ }^{128}$. Matthew C. Wyatts Reiterstandbild zog indessen massive öffentliche Kritik auf $\operatorname{sich}^{129}$. Der Regierungswechsel im Juni 1846 führte kurzzeitig eine regelrechte Entscheidungskrise herbei, als sich der First Commissioner der neuen liberalen Regierung, Lord Morpeth, besorgt zeigte angesichts der desaströsen Resonanz, die das Denkmal ausgerechnet im Kreis der Subskribenten hervorgerufen hatte ${ }^{130}$. Dessenungeachtet wurde die Reiterstatue auf dem Triumphbogen an Hyde Park errichtet: zum einen, da die Monarchin sich durch ihr ursprüngliches Votum gebunden $\operatorname{sah}^{131}$, zum ande-

${ }^{122}$ Vgl. Nelson Memorial Committee, Minute Book, 1838-1844, PRO Work 6/119, Meeting 11. April 1838.

${ }^{123}$ Vgl. The Times, 18. Februar 1839, S. 5; 25. Februar 1839, S. 3; The Times, 11. März 1839, S. 3 und August B. GraNVILLE, A Letter to his Grace the Duke of Wellington on the Nelson Memorial and The Report of the Sub-Committee; with a double plate of Mr. Railton's and the Cast-Iron Corinthian Column, London 1839, S. 8; John GOLDICUTT, The Competition for the erection of the Nelson Monument critically examined, London 1841, S. 7; Thomas HOPPER, Design for the Nelson Testimonial with some observations, London 1839, S. 5; Report from the Select Committee on Trafalgar Square together with the Minutes of Evidence taken before them, and Appendix, 27. Juli 1840, HoC PP Session 1840, $\mathrm{N}^{\circ} 548$, Bd. 12, $\mathrm{N}^{\circ} 548$, hier S. IV; The Times, 24. Juni 1839, S. 5; ibid. 15. Juli 1839 , S. 5.

${ }^{124} \mathrm{Vgl}$. Report from the Select Committee, S. II.

${ }^{125}$ Vgl. Report from the Select Committee, S. 23-29.

${ }^{126}$ Vgl. Protokoll der Sitzung vom 28. Mai 1838, in: Wellington Statue, in: HoC PP, Paper $\mathrm{N}^{\circ} 446$, Bd. 43, S. 345ff., hier S. 6f. Vgl. zur Initiative MUNSELL, The Victorian Controversy.

${ }^{127}$ Vgl. Melboume an Rutland, 30. Mai 1838, in: ibid. S. 3.

${ }^{128} \mathrm{Vgl}$. B.C. Stephenson vom Board of Commissioners of Woods an Forests an das Komitee, 14. Juni 1838, in: ibid. S. 4f.

${ }^{129}$ Vgl. Petition an Rutland, 22. Juni 1838, in: Wellington Statue, in: HoC PP, Paper No 553, Bd. 43, S. 7. Vgl. auch in PRO Work 20/4/2 [up].

${ }^{130}$ Vgl. Brief des First Comissioners Morpeth an Rutland, 5. August 1846, in: Wellington Statue, in: HoC PP Paper N ${ }^{\circ}$ 577, Bd. 57, S. 217 ff., hier S. 2 f.

${ }^{131}$ Vgl. ibid. 
ren, nachdem der Duke seine anfängliche Zurückhaltung ${ }^{132}$ aufgab und Mißfallen angesichts der öffentlichen Erwägungen äußerte, das Denkmal bald wieder abzubauen ${ }^{133}$. Die Monumentalisierung der Kultfigur noch zu deren Lebzeiten, wie sie sonst weder in Paris noch in Berlin zustande kam, folgte außergewöhnlichen Entscheidungsregeln, versah nämlich am Ende nicht macht-, sondern prestigepolitisch die Kultfigur selber an Monarchin und Regierung vorbei mit der Kompetenz der Letztinstanz. Freilich entfaltete sich diese Wirkmacht des »Helden« nur, indem die weitreichende Popularität gleichsam als Funktionserfordernis des Kults veranschlagt und so eingestanden wurde, daß die Denkmalstiftung nicht an der "public opinion ${ }^{134}$ vorbei manipulativ verordnet werden konnte, sondern nicht zuletzt auch zu deren Bedingungen zu erfolgen hatte.

Monarchische Überformungen bereits angelaufener Initiativen kamen in London nicht anders als in Berlin, dann aber vor allem dadurch zustande, da $B$ die Denkmalstifter die Nähe und Involvierung der Krone regelrecht betrieben. So befürworteten Anfang der 1860er Jahre mehrere einflußreiche "gentlemen« der Kapitale um den Londoner Lord Mayor William Cubitt ein Prince Albert Memorial, das während der 1870er Jahre im Hyde Park aufgestellt wurde ${ }^{135}$. »Design« und »mode« des Monuments sollten ausdrücklich in Rücksprache mit der Monarchin bestimmt werden ${ }^{136}$. Victoria schlug daraufhin als künftigen Standort den Hyde Park vor ${ }^{137}$, und berief eine Kommission unter anderem mit Lord Mayor Cubitt, die das Projekt leiten sollte ${ }^{138}$. Mit dieser Personalauswahl verstand es die Königin, sich die metropolitane Initiative anzueignen, ohne sie zu brüskieren. Die städtischen Initiatoren sahen prompt von der Bildung des zunächst anvisierten Subkomitees ab und stellten den bis dahin zu-

${ }^{132}$ Vgl. Wellington an den Tory Croker, 19. Dezember 1846, in: The CROKER Papers 18081857, hg. v. Bernard POOL, London 1884, ND 1967, S. 212; Wellington an Croker, 18. Mai 1846, in: Louis J. JENNINGS (Hg.), The CROKER Papers. The Correspondence and Diaries of the late John Wilson CROKER (...) 1809 to 1830 , Bd. 3, London ${ }^{2} 1885$, S. 122. Vgl. auch Russells Votum in der Debatte des HoC am 1. Juli 1847, in: Hansard $3^{\text {rd }}$ s. 93 (1847) Sp. 1079-1080.

${ }^{133}$ Vgl. dieselbe Parlamentsdebatte, ibid. Sp. 183 und The Times, 13. Juli 1847, S. 5.

${ }^{134}$ Russell am 1. Juli 1847 (s.o.), Hansard $3^{\text {rd }}$ s. 93 (1847) Sp. 1079.

${ }^{135}$ Vgl. The Times, 2. Januar 1862, S. 7. Vgl. auch DARBY, SMITH, The cult of the Prince Consort, S. 44-57; BAYLEY, The Albert Memorial; [An.,] Proposed National Memorial to His Royal Highness the Prince Consort, London o. J., S. If.

${ }^{136} \mathrm{Vgl}$. At a public meeting (...) on the $14^{\text {th }}$ of January, 1862, in: [An.,] Proposed National Memorial, S. 3; The Times, 23. Januar 1862, S. 8; The Memorial, HoL, 7. Februar 1862, in: Hansard $3^{\text {rd }}$ S., S. 165 (1862) Sp. 88-89 und The Memorial, HoL, 10. Februar 1862, Hansard ibid. Sp. 118f.

${ }^{137}$ Vgl. Schreiben der Queen Victoria an den Lord Mayor als Komiteevorsitzenden vom 19. Februar 1862, in: The Times, 22. Februar 1862, S. 5 und [An.,] Proposed national memorial, S. 6f., hier S. 7.

${ }^{138} \mathrm{Vgl}$. The Times, 27. Februar 1862, S. 5. 
sammengetragenen Fonds der monarchisch bestellten Beraterkommission zur Verfügung ${ }^{139}$. Die Kommission zog später mehrere Architekten hinzu ${ }^{140}$ und legte der Queen erste Entwürfe vor ${ }^{141}$, nicht ohne klar das Modell George Gilbert Scotts von der Royal Academy zu favorisieren ${ }^{142}$ und dafür auch erfolgreich den Konsens der Monarchin einzuwerben ${ }^{143}$. Victoria behielt sich währenddessen das Recht vor, Künstler mit den übrigen zum Denkmalkonzept gehörenden Skulpturengruppen zu beauftragen ${ }^{\mathrm{I}}{ }^{4}$. Nachdem sich 1872 der städtische Fund aufgelöst hatte, verblieb die übrige Koordination der erst 1876 vollständig abgeschlossenen Arbeiten ganz beim königlichen Komitee ${ }^{145}$.

Insgesamt hielt sich Queen Victoria aber bis auf dieses spezielle Interesse am Prince Albert-Denkmal anders als die interventionsfreudigen preußischen Regenten symbolpolitisch ungleich stärker zurück. In öffentliche Denkmalerrichtungsverfahren mischte sich eher ihr Sohn Edward VII. wieder ein, indem er etwa 1907 anläßlich der Aufstellung des Denkmals für den Oberbefehlshaber der Armee, Duke of Cambridge, das exakte Inaugurationsdatum festlegte und über das Arrangement des Festplatzes entschied ${ }^{146}$. Singulär blieb demgegenüber das Ausmaß monarchischer Involvienung im Falle des großen Victoria Memorial, das nach etwa zehnjähriger Entstehungszeit 1911 vor Buckingham Palace eingeweiht werden konnte. Die monarchisch dominierte Initiative wurde noch im Jahr ihres Todes 1901 von einem Komitee auf den Weg gebracht, dessen Mitglieder Edward eigens nominiert hatte und dem unter dem Vorsitz des konservativen Premiers Salisbury neben dem amtierenden First Commis-

${ }^{139}$ Vgl. ibid. und Komiteebericht, 12. November 1863, RA Vic. Add. H. 5, Bl. 2-4, hier Bl. 2 sowie Extract from Deed signed by Her Majesty the Queen appointing the Executive Committee of the Prince Consort Memorial vom 21. September 1864, PRO Work 16/362 [up].

140 Vgl. Eastlake an Grey am 9. Mai 1862, RA Vic. Add. H. 1, B1. 215 b.

${ }^{141} \mathrm{Vgl}$. The Builder, 4. April 1863, S. 233.

${ }^{142}$ Vgl. Third Report of the Prince Consort Memorial Committee, London 25. März 1863, RA Vic. Add. H. 2, Bl. 435-437, hier Bl. 437.

${ }^{143} \mathrm{Vgl}$. Grey im Namen der Queen an Eastlake, 22. April 1863, RA Vic. Add. H. 2, Bl. 438. Bereits 1865 wurde aber die Idee der "Albert Hall « nach Plänen von Henry Cole wieder aufgenommen; die Grundsteinlegung erfolgte am 2. April 1867, die Fertigstellung und Eröffnung bis 1871, vgl. [An. (Hg.),] Fifty years of public work of Sir Henry Cole, K.C.B., accounted for in his deeds, speeches and writings, Bd.1, London 1884, S. 357 364.

144 Deren Ausarbeitung machte Victoria aber vom Votum Scotts abhängig. Vgl. Grey namens der Queen an Eastlake, 15. März 1864, RA ibid. BI. 785; G.G. SCOTT (Hg.), Personal and professional recollections by the late Sir George Gilbert Scott, London 1879, repr. New York 1977, S. 265.

${ }^{145}$ Vgl. James DAFFORNE, The Albert Memorial, Hyde Park: its history and description, London o. J. [1878], S. 42.

${ }^{146} \mathrm{Vgl}$. Bericht aus dem Office of Works an den Chief Commissioner of Police am 21. Mai 1907; Bericht an den Westminster City Council vom 23. Mai 1907, PRO Work 20/58 [up]. 
sioner Akers Douglas der frühere konservative Premier Arthur James Balfour (1902-1905), aber auch sein liberaler Nachfolger Sir Henry CampbellBannerman (1905-1908), Kolonialminister Joseph Chamberlain und der Liberale Earl of Rosebery angehörten ${ }^{147}$. Mit den Präsidenten der Royal Academy und des Royal Institute of British Architects zog er hochrangige Spezialisten hinzu $^{148}$. Darüber hinaus bemühte man sich um eine dezidiert britische Repräsentativität, indem drei Architekten aus London und je einer aus Dublin und Edinburgh um Pläne für die Umgestaltung der Mall ersucht wurden ${ }^{149}$. Dessen ungeachtet kritisierten zahlreiche Architekten und Bildhauer das Verfahren ${ }^{150}$, weil sie die solchermaßen betriebene Repräsentativität nurmehr für deklaratorisch erachteten, solange die Beteiligungschancen am Denkmal auf enger Selektion beruhten ${ }^{151}$. Daß auch die Kolonien und Dominions zur materiellen Beteiligung am Nationaldenkmal eindringlich aufgefordert worden waren, ohne daß sie entscheidungspolitisch einbezogen worden wären, entging dabei der öffentlichen Kritik. Unterdessen überwachte Edward VII. durch regelmäßige Besuche im Atelier des mit der Monarchinnenfigur beauftragten Künstlers Thomas Brock in einer dem Berliner Prozedere durchaus ähnlichen Weise die bildprogrammatische Umsetzung des Denkmalprojektes ${ }^{152}$.

Abgesehen davon waren grundsätzlich Komitees, die Standorte in Kronbesitz anvisierten, auf das Plazet der Monarchin bzw. des Office of Works angewiesen, das auf diesem Wege zugleich Mitsprache erhielt. Der vom Komitee

${ }^{147}$ Vgl. Queen Victoria Memorial. Report 1901-1911, London 1911, S. 1.

${ }^{148} \mathrm{Vgl}$. Ibid. S. 2. Die Initiatoren arbeiteten erkennbar auf ein möglichst repräsentatives und inklusives Profil des Stifterkomitees hin und erhielten in der Tat Unterstützung von zahlreichen Parlamentariern und Lords beider großen Parteien, Mitgliedern des Londoner Council (Aldermen), dem Bishop of Hereford, einem Erzdiakon, dem Dean of Westminster und St Paul's, dem »Chief Rabbi« der jüdischen Gemeinde, dem Leiter der Bank of England, dem Vorsitzenden des Stock Exchange und dem Präsident der Handelskammer. Vgl. The Times, 27. März 1901, S. 8. Insofern standen parteiübergreifender Konsens, hauptstädtisches Kapital und die Vertreter der großen Denominationen von Beginn an geschlossen hinter dem Projekt.

${ }^{149}$ Vgl. Queen Victoria Memorial. Report, S. 4. Thomas Brock von der Royal Academy fertigte die Entwürfe für das Denkmal.

${ }^{150}$ Vgl. The Times, 1. Mai 1901, S. 13; The Saturday Review, 6. April 1901, S. 435-436; Philip A. ROBSON in einem Brief an das Royal Institute, in: Journal of the Royal Institute of British Architects 8 (11. Mai 1911) S. 324-330.

151 Vgl. Ibid. S. 326 und 328: »The Committee had invited the whole of the British Empire to contribute to the funds, therefore it was the duty of the trustees of the money to see that they got the very utmost and the very best possible that money could purchase or genius devise. To obtain that they must search the Empire through to find out where the best could be found. (...) Therefore let there be an open door in this matter, so that everyone throughout the Empire could enter and take part in this great national project which concerned them all."

${ }^{152}$ Vgl. Queen Victoria Memorial. Report, S. 6; Viscount Esher als Präsident des Executive Committee am 22. Januar 1914, PRO Works 20/104 [up]. 
für das Lord Derby-Denkmal erbetene Aufstellungsort vor dem Parlament ${ }^{153}$ wurde vom Commissioner of Works nur unter der Bedingung zugestanden, $\mathrm{da} ß$ die Statue dann den Proportionen nach auf die anderen hier aufgestellten oder geplanten Statuen für Sir Robert Peel und Lord Palmerston abgestimmt zu werden hatte ${ }^{154}$. Dem Komitee blieb nur, sich etwas widerwillig auf diese Regelung einzulassen ${ }^{155}$. Neben Denkmälern wie der Derby-Statue nahm das Office auch Denkmäler nach ihrer Errichtung in seine Obhut, die nicht auf "crown land" plaziert waren und insofern zunächst nicht in seinen Kompetenzbereich fielen, dem Office aber von den Stiftern unterstellt und mit dieser Zuweisung einmal mehr als "national monuments « gehandelt wurden ${ }^{156}$. Die Kompetenz des Office reichte selbst bis zur Translozierung von bereits errichteten Monumenten ${ }^{157}$.

Die Mitgliedschaft der First Commissioner im Kabinett zog allerdings nicht nachweislich eine drastische Politisierung des Entscheidungsverfahrens nach sich. Als das Komitee zur Errichtung einer Londoner Statue für den Konservativen Robert Peel beim Department of Works eine Genehmigung zur Aufstellung auf dem Palace Yard in Westminster unmittelbar neben den Parlamentsgebäuden beantragte, der als Teil des Palace of Westminster zu den Besitzungen der Queen gehörte ${ }^{158}$, wurde es zwar zunächst abschlägig beschieden. Daß der dem Koalitionskabinett von Whigs und Peelites angehörende First Commissioner aus politischen Motiven heraus entschied, zeichnete sich dabei aber nicht $a^{159}$. Nach Standortkorrekturen war es später ohnedies der Commissioner einer Whig-Regierung, der die Aufstellung am Eingang von New Palace Yard gestattete $^{160}$. Ebenso erging die Genehmigung von Denkmälern für die beiden konservativen Premiers Lord Derby $1871^{161}$ und Benjamin Disraeli im

${ }^{153} \mathrm{Vgl}$. The Times, 21. Juli 1879, S. 10.

${ }^{154} \mathrm{Vgl}$. Department of Works an den Komiteevorsitzenden Pakington, 8. August 1871, PRO Work 20/42 [up].

${ }^{155}$ Vgl. The Times, 28. April 1873, S. 7.

${ }^{156}$ Vgl. so geschehen im Falle des Denkmals für den Militär Sir Hugh Rose, Baron Strathnaim von 1895; vgl. Mitteilung des Office of Works an die Treasury, 8. August 1895 PRO Work 20/76 [up].

${ }^{157} \mathrm{Vgl}$. so im Falle einer Statue für den Feldmarschall Robert C. Napier, das einem Edward VII.-Denkmal weichen mußte. Vgl. Brief aus dem Office of Works an Boehm vom 31. Juli 1890, PRO Work 20/63 [up], und Office of Works an den Lord Mayor von London, 30. April 1890, PRO ibid.; Sir F. Ponsonby an Sir Warren Fisher von der Treasury, 9. Februar 1921, PRO Work 29/135 [up].

${ }^{158}$ Vgl. Lord Cardwell an den First Commissioner William Molesworth, 22. März 1853, PRO Work 20/31 [up].

${ }^{159} \mathrm{Vgl}$. Schreiben des First Commissioner of Works und radikalen Reformpolitikers Molesworth an Cardwell, 22. März 1853, PRO ibid.

${ }^{160}$ Vgl. Mitteilung des Liberal-Conservative Lord Cardwell an Cowper, 26. März 1861, PRO ibid.

${ }^{161} \mathrm{Vgl}$. Department of Works an den Komiteevorsitzenden Pakington, 8. August 1871, PRO Work 20/42 [up]. 
Jahre $1883^{162}$ während liberaler Legislaturen ${ }^{163}$. Selbst im Falle des umstrittenen und nach langer Vorlaufphase erst 1899 realisierten Cromwell-Projekts zeichneten sich keine dezidiert parteipolitischen Entscheidungsmechanismen ab. Schon 1845 waren erste Pläne aufgetaucht ${ }^{164}$, erhitzte Diskussionen verzögerten aber eine Entscheidung ${ }^{165}$. Erst 1895 konnte die liberale Regierung unter Lord Rosebery die Bewilligung parlamentarischer Gelder für ein Cromwell-Denkmal durchfechten ${ }^{166}$, bevor heftige Opposition der irischen Abgeordneten den Plan kippte ${ }^{167}$. Wenig später erhielt der First Commissioner Herbert Gladstone die Einzelspende eines anonymen Gönners, die die Denkmalerrichtung nun auf privater Basis als Schenkung an den Staat ermöglichen sollte $^{168}$. In der Presse hielt sich hartnäckig das Gerücht, daß es sich dabei um niemand anderen als Rosebery selbst handelte ${ }^{169}$, während eine entsprechende offizielle Bestätigung ausblieb ${ }^{170}$. Obgleich zu den Opponenten gegen das Denkmal zahlreiche Konservative einschließlich Balfours gehört hatten, unternahm das seit dem 25. Juni 1895 amtierende konservative Kabinett Salisbury keinerlei Anstrengungen, in das laufende Verfahren einzugreifen, so daß der Regierungs- und der damit verbundene Amtswechsel an der Spitze des Office of Works für den Gang der Initiative folgenlos blieben ${ }^{171}$. Eine Petition, mit

${ }^{162}$ Vgl. Schreiben des Denkmalkomiteevorsitzenden Sir Strafford Northcote an den First Comissioner Shaw Lefevre, 29. Juli 1881, PRO Work 20/48 [up], und The Times, 24. Mai 1882, S. 8.

${ }^{163} \mathrm{Vgl}$. Mitteilung aus dem Office of Works an Strafford am 2. August 1881, PRO ibid.

${ }^{164}$ Vgl. Supply. Statues, Sitzung des HoC vom 30. Juli 1845, in: Hansard 82 (1845) Sp. 1256.

${ }^{165} \mathrm{Vgl}$. dazu auch John BELL, Memoranda in letters to R.H. Soden Smith, relating to his statue of Oliver Cromwell, 1890 [MS, up]; The Times, 14. November 1862, S. 7; Parliament. Statue to Oliver Cromwell. Question, Sitzung des HoC vom 12. März 1868, in: Hansard 190 (1867-8) Sp. 1450-1451.

${ }^{166} \mathrm{Vgl}$. A statue of Oliver Cromwell, Sitzung des HoC, 11. Februar 1895, in: Hansard $4^{\text {th }} \mathrm{s}$. 30 (1895) Sp. 452; The proposed statue, Sitzung des HoC vom 14. Februar 1895, in: Ibid. Sp. 744; The Saturday Review, 21. Oktober 1899, S. 510-511, hier S. 510.

${ }^{167} \mathrm{Vgl}$. The Evening Standard, 18. Juni 1895, S. 2; The Standard, 18. Juni 1895, S. 6.

${ }^{168}$ Vgl. The Daily Chronicle, 20. Juni 1895, S. 5; Memorandum des First Commissioner of Works Herbert Gladstone vom Juni 1895, PRO Work 20/100 [up].

${ }^{169}$ Vgl. The Manchester Guardian, 15. November 1899, S. 7; The Independent, 2. November 1899, S. 322; The Cromwell Statue, HoL am 21. Juni 1900, in: Hansard $4^{\text {th }}$ s. 84 (1900) Sp. 588-598, hier S. 597. Über die Schenkung bestand noch 1937 Unklarheit, als eine Anfrage vom 24. November 1937, die eine Urheberschaft Rosberys nahelegte, vom Office of Works am 6. Dezember 1937 erneut mit der »anonymous donor «-Formel beantwortet wurde, vgl. PRO Work 20/115 [up].

${ }^{170} \mathrm{Vgl}$. Memorandum des First Commissioner of Works H. Gladstone vom Juni 1895, PRO Work 20/100 [up].

${ }^{17}$ Vgl. Akers Douglas an Gladstone, 8. Juli 1898, PRO Work [up]; Statue of Oliver Cromwell, Sitzung des HoC, 25. April 1899, in: Hansard $4^{\text {th }}$ s. 70 (1899) Sp. 515; The Cromwell statue, Sitzung des HoC, 11. Mai 1899, in: Ibid. Sp. 956; The Cromwell Statue, Sit- 
der die Errichtung der Statue verhindert werden sollte ${ }^{172}$, versuchte der First Commissioner Akers Douglas für nichtig zu erklären, indem er klarstellte, daß die konservative Regierung für die Annahme geschenkter Statuen oder Büsten das Parlament nicht zu befragen habe ${ }^{173}$. Daß die Regierung bis zuletzt mit erheblichem Widerstand gegen das Denkmal rechnen mußte, bewog sie am Ende zu einer Strategie der Konfliktvermeidung, und so erging aus dem Office of Works die Weisung, daß die Cromwell-Statue 1899 »without any ceremony« aufzustellen sei ${ }^{174}$.

Sobald städtische Aufstellungsorte im Zuständigkeitsbereich nicht der Krone, sondern des MBW von den Komitees anvisiert wurden, involvierte dies auch das städtische Gremium. Als etwa die Inititatoren des Mill-Denkmals das Board um Gewährung eines Standorts am Victoria Embankment angingen ${ }^{175}$, knüpfte dieses seine Zusage an die Bedingung, daß das »design of the pedestal and statue « dem Board zuvor bekannt gemacht und eigens genehmigt werden mußte ${ }^{176}$. Der Komiteeantrag wurde nach dem gängigen Verfahren zunächst an das Works and General Purposes Committee weitergeleitet, das als eines der Subkomitees unter der Kontrolle des Board arbeitete und den Vorschlag prüfen lie $B^{177}$. Entsprechende Kompetenzen erhielt auch die City, sobald Denkmalstifter ihr gehörendes Areal als Standort auswählten ${ }^{178}$.

\section{Konturen von Stifterprofilen}

Ebensowenig wie die Denkmalgenesen sind die Initiatorengruppen aller in der Folge analysierten Denkmalsetzungen im einzelnen auszubreiten. Statt dessen sollen kursorisch Konturen typischer Denkmalstifter in den Kapitalen dargestellt werden. Die Aussagen über die Sozialprofile der Denkmalstifter müssen ohnedies vorsichtig getroffen werden. Dies nicht nur, weil flächendeckende

zung des HoL, 28. April 1899, in: Ibid. Sp. 809-812 (Anfrage des liberalen Lord Elcho, Earl of Wemyss).

172 Vgl. Statue of Oliver Cromwell, Sitzung des HoC, 2. August 1899, in: Hansard 75 (1899) Sp. 1150.

${ }^{173}$ Vgl. Cromwell's statue, Sitzung des HoC, 3. August 1899, in: Ibid. Sp. 1296-1298.

${ }^{174} \mathrm{Vgl}$. Schreiben aus dem Office of Works vom 10. November 1899, PRO Work 20/100 [up]

$175 \mathrm{Vgl}$. Meeting of the MBW, 21. November 1873, in: Minutes of Proceedings of the MBW Juli-Dezember 1873, S. $502 \mathrm{f}$.

${ }^{176} \mathrm{Vgl}$. Meeting of the MBW, 19. Dezember 1873, in: Ibid. S. 654f.

17 Vgl. ibid. Auch die Modellskizze des Denkmals wurde vom Board eigens bewilligt. Vgl. Meeting of the MBW, 28. September 1877, in: Minutes of Proceeding of the MBW JuliDezember 1877, 304/59, und Meeting of the MBW, 19. Oktober 1877, in: Minutes of Proceeding of the MBW ibid. 402/9.

${ }^{178}$ Vgl. so im Falle eines Denkmals für den Erfinder des »penny postage«-Systems Rowland Hill vor dem Royal Exchange; vgl. The Times, 22. Mai 1880, S. 2. 
bzw. auswertbare Dokumentationen häufig fehlen ${ }^{179}$, sondern mehr noch, weil mit den Stifter- nur zum Teil auch bereits Subskribentenprofile erfaßt sind, die aber erst eine aktive materielle Beteiligung am jeweiligen Denkmal erkennen lassen. Umgekehrt kamen allerdings zeitgenössische Subskribentenlisten auch nicht ausschließlich auf dem Hintergrund freiwilliger und spontaner Partizipationsakte, sondern im Kontext komplexer sozialer Vernetzungen und prestigepolitischer Signalhandlungen zustande ${ }^{180}$, so daß ihre Bedeutung nicht überschätzt werden darf. Es kann also nur darum gehen, Konturen von Stifterprofilen zumindest näherungsweise zu skizzieren.

\subsection{Paris}

1. In der Zeit des Zweiten Empire standen zunächst die wenigen Pariser Denkmäler, die außerhalb direkter Auftragsvergabe und Anweisung Napoleons III. überhaupt zustande kamen, am ehesten militärischen Initiatorenzirkeln nahe. Zur Errichtung eines Denkmals für den Militär und Mediziner Dominique Larrey 1850 im Innenhof des ehemaligen Militärkrankenhauses Val-deGrâce bildete sich bereits 1842 wenige Monate nach Larreys Tod eine entsprechende Kommission unter Vorsitz des Kommandanten des Hôtel national des Invalides, Petit, dem Vertreter der Armee, der medizinischen Militärverwaltung und der medizinischen Wissenschaft angehörten ${ }^{181}$. Auch dem Subskriptionskomitee für das 1863 errichtete Denkmal des Adoptivsohns Napoleons I., Eugène de Beauharnais, gehörten u.a. 12 Generale, vier Obristen (Colonnels), ein Admiral und der Militärgouverneur des Palais du Luxembourg an, daneben aber auch vier Deputierte und ein Mitglied des Conseil Municipal ${ }^{182}$. Gänzlich zivile und spezifisch akademische Profile wiesen demgegenüber die Initiatorengruppen auf, die hinter den beiden während der 1860er Jahre entstandenen

${ }^{179}$ Die Auswertbarkeit von Subskriptions- oder Komiteemitgliederlisten in der Tagespresse oder Broschüren tendiert gegen Null, sobald Berufsbezeichnungen fehlen, die erst eine soziale Zuordnung ermöglichten. Faktisch trifft dies aber für die Mehrheit der verglichenen Fälle zu. Zum Quellenproblem der Subskriptionslisten bereits Kapitel I.2.2.

${ }^{180}$ Vgl. so v.a. TACKE, Denkmal im sozialen Raum, S. 196-200.

${ }^{181} \mathrm{Vgl}$. Schreiben des Ministre de la Guerre an den Ministre de l'Intérieur vom 22. Mai 1846, AN F ${ }^{\text {le }}$ I 167 Dossier: Autorisation d'ériger une statue dans la cour du Val de Grâce, au Baron Larrey, 23 mai -15 juillet 1846; Compte rendu des travaux de la commission de souscription pour le Monument de Larrey érigé au Val-de-Grâce le 8 août 1850, Paris 1850, S. 6. Der Kommission gehörten neben zwei Militärintendanten, drei Mitgliedern des Conseil de santé des armées und sechs officiers de santé principaux der Pariser Militärhospitäler aber auch ein Mitglied des Institut d'Égypte und der Académie des inscriptions et belles-lettres, je zwei Mitglieder der Académie des sciences und des Conseil de salubrité, vier Mitglieder der Académie nationale de médecine und Seinepräfekt Rambuteau an.

${ }^{182} \mathrm{Vgl}$. Souscription Nationale. Monument à élever à la mémoire du Prince Eugène Beauharnais, Paris 1854 [up]. 
Statuen für den Agronomen Antoine Parmentier und den Chemiker Nicolas Vauquelin $\operatorname{standen}^{183}$.

2. Nach 1871 vervielfältigten sich die Entstehungskontexte von Denkmälern merklich. Häufiger trat jetzt der Conseil Municipal als städtischer Initiator auf - entweder in Verbindung mit dem departementalen Gremium des Conseil général de la Seine, wie im Falle der allegorischen Gruppe der »Défense de Paris en $1870 \aleph^{184}$, oder, indem einzelne seiner Mitglieder Projekte betrieben. So gründete eines der Conseil-Mitglieder ein aus namhaften Schriftstellern, Intellektuellen und Akademikern rekrutiertes Komitee zur Ehrung des Romanciers Alexandre Dumas ${ }^{185}$. Auch die Errichtung der République-Figuren von $1883^{186}$ und 1899 auf der Place de la Nation ${ }^{187}$ oder das Danton-Denkmal ${ }^{188}$ verdankten sich entsprechenden Initiativen seitens des Conseil.

Zahlreich und dominant wurden jene Denkmalprojekte, die an der Verbindungsstelle zwischen Conseil municipal und Parlament entstanden. So ging die Initiative zur Errichtung des 1885 eingeweihten Denkmals für den Quarantehuitard Alexandre Ledru-Rollin von einem vor allem aus Senatoren, Deputierten und Mitgliedern des Conseil Général de la Seine wie des Conseil Municipal von Paris bestehenden Komitee aus, dem Victor Hugo als ehemaliger Senator, zahlreiche namhafte Vertreter der republikanischen Linken wie Louis Blanc, Charles Floquet und Eugène Spuller als Deputierte sowie Mitglieder beider Conseils angehörten ${ }^{189}$. Mit einem ähnlichen Stifterprofil glückte auch

${ }^{183}$ Vgl. die Mitteilung des Ministre de l'Intérieur an den Ministre de l'Agriculture et du Commerce vom 27. März 1860, AN F 168 Dossier: Projet des décrets (...) autorisant l'érection de statues à Parmentier et à Vauquelin. Comités crées pour l'érection de ces statues. Correspondance [up].

${ }^{184} \mathrm{Vgl}$. Préfecture du Département de la Seine. Concours pour l'érection, au rond-point de Courbevoie d'un Monument allégorique de la Défense de Paris en 1870, S. 2, AP VR 161 Dossier: Concours pour l'érection au rond-point de Courbevoie d'un monument.

${ }^{185}$ Vgl. [An.,] Le monument d'Alexandre Dumas, œuvre de Gustave Doré. Discours prononcé devant le monument le jour de l'inauguration. Poésies récités le même jour sur différents théâtres ou distribuées aux assistants avec une préface par $\mathbf{M}$. Alexandre Dumas, fils, $\mathbf{P a}$ ris $1883, \mathrm{~S}$. IIf.

${ }^{186} \mathrm{Vgl}$. Proposition pour la mise au concours d'une statue de la République, séance du 30 mars 1878, in: CMPV, Année 1878, S. 228f.

${ }^{187} \mathrm{Vgl}$. VAUDREMER, Concours pour l'érection, place de la République, d'une Statue monumentale de la République. Rapport présenté au nom du Jury chargé duclassement des esquisses, 3 novembre 1897, Paris 1879; Ulysse PARENT, Rapport, in: CMRD, Année 1880, Imp. $\mathrm{N}^{\circ} 85$.

${ }^{188} \mathrm{Vgl}$. Rapport par M.DELHOMME (...), demandant l'érection d'une statue à Danton (28. Dezember 1887), in: CMRD, Année 1887, Imp. $N^{\circ} 42, \mathrm{~S} .1-4$, hier S. 1.

${ }^{189} \mathrm{Vgl}$. undatiertes Schreiben des Komitees an den Präsidenten des Conseil général de la Seine, $\mathrm{AN} \mathrm{F}^{\mathrm{lc}}$ I 168 Dossier: mars 1882-février 1884 , érection d'une statue à Ledru-Rollin, place Voltaire. Ähnlich das Initiatorenprofil des "Comité du Monument Sadi-Carnot et de l'Alliance Franco-Russe« um das am Ende gescheiterte Projekt für den ehemaligen Staatspräsidenten Sadi Carnot; vgl. Souscription nationale pour l'érection à Paris d'un monu- 
das große Denkmalprojekt zugunsten des republikanischen Ministerpräsidenten Gambetta, das ein Komitee aus 30 Senatoren und 50 Deputierten - darunter die späteren Staatspräsidenten Sadi Carnot und Félix Faure und der künftige Ministerpräsident Charles Floquet - sowie aus sechs Conseillers Municipaux, acht Vertretern großer Pariser Zeitungen und 15 Vertretern von Provinzzeitungen verfolgte ${ }^{190}$. Erweitert um Künstler und Angehörige der freien Berufe, entsprach diesem Erscheinungsbild auch das Stifterprofil im Umfeld der 1889 eingeweihten Rousseau-Statue ${ }^{191}$.

Gelegentlich entstanden auf diesem Wege eindeutig politische Profile, wenn etwa das Denkmal für den Ministerpräsidenten Charles Floquet, das 1909 am Boulevard Richard-Lenoir enthüllt wurde, der Parti Républicain Radical Socialiste und damit eine Partei der linksrepublikanischen Mitte betrieb ${ }^{192}$. In diesem Sinne verstanden sich auch die Initiativen der republikanischen Ligue Française de l'Enseignement, die zunächst im Juli 1900 mit Jean Macé ihren Gründer ${ }^{193}$ und zehn Jahre später den republikanischen Ministerpräsidenten Ferry feierte ${ }^{194}$. Für das Denkmal zugunsten des Ministerpräsidenten WaldeckRousseau von 1910 im Jardin des Tuileries setzte sich die Alliance républicaine démocratique ein, die er selbst im Oktober 1901 als lose Gruppierung finanzkräftiger und einflußreicher gemäßigt linksrepublikanischer Kräfte ge-

ment à la mémoire de Sadi-Carnot, DAC Dossier: Sadi Carnot; AN F 4855 Dossier: Monument de Sadi Carnot et de l'Alliance franco-russe 18 oct.-27 nov. 1913 [up].

190 Vgl. Le Temps, 22. März 1883, S. 2.

191 Eine lange Vorgeschichte von Anläufen zur Denkmalerrichtung seit Rousseaus Tod 1778 ging voraus. Zu den drei Initiativen (1790, in den Jahren II und VII) vgl. auch Les soussignés (...), séance du 27 février 1879, in: CMPV, Année 1879, $1^{\text {er }}$ sem., S. 215. Vgl. Armand AMANN, Les monuments à Jean-Jacques Rousseau, où la sculpture pérsécutée, in: C'est la faute à Rousseau. Révolution, Romantisme, République. L'image de Jean-Jacques Rousseau, Chambéry, Genève 1990 [AK Musée Savoisien Chambéry, Musée d'Art et d'Histoire Genève], S. 13-17; zur Revolutionsphase Gisela GRAMACCIN, Sur le projet d'élever un monument en l'honneur de Rousseau, in: [Musées nationaux,] La Révolution Française et l'Europe 1789-1799, Bd. 3, Paris 1989, S. 893-902; Ernest HAMEL, La statue de Jean Jacques Rousseau, Paris ${ }^{2} 1868$, S. 6-9, 15, 20-26; zum Komitee: Concours pour l'érection d'une statue à Jean Jacques Rousseau, $\mathrm{AN} \mathrm{F}^{21} 4856$ Dossier: Monument Jean-Jacques Rousseau; CASTELlant, Centenaire de la Révolution, S. 73-75. Ihm gehörten nun 37 Senatoren (darunter Scheurer-Kestner, Schoelcher, Camot u. a.), 38 Abgeordnete (darunter Clémenceau, Henry Maret, Marmottan u. a.) sowie 40 Conseillers généraux de la Seine und Conseillers municipaux aus Paris, 8 weitere Munizipalbeamte und $26 \mathrm{Pu}$ blizisten, Literaten und Künstler an. Als Exekutivkommission wirkte außerdem eine vom Abgeordneten Jules Steeg geführte Gruppe mit dem Präsidenten der Pressegewerkschaft, zwei Conseillers und ein Ingénieur des Ponts et Chaussées.

192 Vgl. Mitteilung des Ministre de l'Instruction publique vom 2. September 1908, AN F ${ }^{21}$ 4855 Dossier: Monument Floquet, par Jean Descamps, statuaire, 23 mars 1907-16 septembre 1908.

${ }^{193}$ Vgl. Renvoi (...), séance du 13 juin 1898, in: CMPV, Année 1898, $1^{\text {er }}$ sem., S. 610.

194 Vgl. [An.,] Cérémonie de la Sorbonne en l'honneur de Jules Ferry (20 décembre 1906), Corbeil 1907 [up]. 
gründet hatte ${ }^{195}$. Einseitig am linken Rand des politischen Spektrums blieb im Vergleich dazu das Initiatorenprofil um den Mur des Fédérés, an dem 1871 aufständische Kommunarden von den Versailler Regierungstruppen erschossen worden waren und die 1908 durch Anbringung einer Plakette zum Denkmal umfunktioniert wurde. Hier bildeten ehemalige Kommunarden die treibenden Kräfte ${ }^{196}$, bevor v.a. der Sozialist Joffrin im Namen des Parti ouvrier und eines Comité central révolutionnaire als Fürsprecher des Plans auftra$\operatorname{ten}^{197}$. Darüber hinaus erwies sich die republikanische Presse gelegentlich nicht nur als Unterstützer oder Mit-, sondern auch als Hauptinitiator und verfuhr dann umso erfolgreicher, je eher es ihr gelang, renommierte Republikaner für ein Unterfangen anzuwerben ${ }^{198}$.

Eher einschlägig akademische Profile aus dem Milieu renommierter Wissenschaftsinstitutionen prägten demgegenüber das Erscheinungsbild der Stiftergruppen, die zur Ehrung von Forschern und Naturwissenschaftlern antraten. So wurde das Claude Bernard-Denkmal vor dem Collège de France von 1886 von der Société Biologique initiiert ${ }^{199}$, das Denkmal für den Psychiater und Mediziner Philippe Pinel von der Société Médico-Psychologique ${ }^{200}$, während die Académie des sciences als Initiatorin der Monumente für die Chemiker Lavoi$\operatorname{sier}^{201}$ und Leblanc ${ }^{202}$ auftrat und dabei auch englische, deutsche und belgische Industrielle anwerben konnte ${ }^{203}$.

${ }^{195}$ Vgl. Carnot an den Secrétaire des Beaux-Arts am 20. Februar 1907, AN F 4853 Dossier: Monument à Waldeck-Rousseau, par Marqueste, sculpteur, 6 mars 1906; 4 décembre 1904-15 mai 1926. Vgl. auch Comité du Monument Waldeck-Rousseau. 17 Rue de la Rochefoucauld, Paris, 6 juillet 1910.

${ }^{196} \mathrm{Vgl}$. Ordre du jour (...), séance du 7 décembre 1880, in: CMPV, Année 1880, S. 783-787.

${ }^{197}$ Vgl. Proposition de M. Joffrin, séance du 5 novembre 1883, in: CMPV, Année 1883, $2^{\circ}$ sem., S. 469-471; Discussion de la proposition de M. Joffrin, séance du 23 décembre 1883 , in: Ibid. S. 1164.

${ }^{198}$ Die Denkmalerrichtung für den Poeten Jean Béranger ging von der Zeitung La Chanson aus; vgl. La Chanson, 16. Februar 1879, S. 133-135, AN F ${ }^{21} 4855$ Dossier: Monument à la mémoire de Béranger 16 février 1879-12 maj 1885, poète. Vgl. auch die Beteiligung namhafter republikanischer Gazetten an der Denkmalerrichtung für den Journalisten und Mediziner Théophraste Renaudot, [An.,] Inauguration de la statue de Théophraste Renaudot (1585-1653), Fondateur du Journalisme et des consulations charitables pour les pauvres malades, 4 juin 1893, Paris 1893, S. 3f.; [Eugène HATIN], Enfin! Théophraste Renaudot, aura-t-il la statue qu'il mérite à tant de titres!, Paris 1892, S. 2.

${ }^{199} \mathrm{Vgl}$. [An.,] Souscription publique pour élever un monument à Claude Bernard, Paris 1878, [up].

${ }^{200}$ Vgl. Le Petit Journal, 15. Juli 1885, S. 1.

201 Vgl. Protokoll des Komiteesekretärs Moissan, 7. Februar 1898, AN F ${ }^{21}$ Dossier: Statue de Lavoisier par Barrias, sculpteur, 21 juillet 1894-9 juillet 1900.

${ }^{202}$ Vgl. Le Temps, 29. Juni 1887, S. 2.

${ }^{203}$ Vgl. [An.,] Inauguration de la statue de Nicolas Leblanc à Paris le 28 juin 1887, Paris 1887 (Institut de France. Académie des Sciences), S. 16. Die Initiative zum Denkmal für den Naturwissenschaftler Le Verrier 1889 vor dem Observatoire ging von der 1864 durch Le Verrier gegründeten und seit 1870 als gemeinnützig anerkannten Association scientifi- 
$\mathrm{Ab}$ den 1880er Jahren machten sich gelegentlich leichte soziale Weitungen der Initiatorengruppen bemerkbar. Singulär blieb die Involvierung von Arbeitern in Denkmalinitiativen: Im September 1881 adressierte ein Arbeiter Steckle aus dem 5. Arrondissement einen Brief an den Président du Conseil Municipal, in dem er auf das Schicksal des im 16. Jahrhundert von einer inquisitorischen Kirche auf der Place Maubert verbrannten Druckers Étienne Dolet hinwies und die Idee einer Denkmalerrichtung aufbrachte ${ }^{204}$, auf die sich der Präsident in der Tat einlie ${ }^{205}$. Das 1889 errichtete Denkmal für den Quarantehuitard François Raspail ging auf ein Komitee zurück, dem neben 15 Abgeordneten, zwei Mitgliedern des Conseil général de la Seine und zwei des Conseil Municipal auch ein Unternehmer, drei Kaufleute, zwei Mechaniker, ein Tischler, ein Handelsvertreter und ein Handelsangestellter angehörten ${ }^{206}$, so daß das Profil hier zugunsten wirtschafts- und kleinbürgerlicher Gruppierungen geweitet schien ${ }^{207}$. Diesem Trend stand aber umgekehrt durchaus auch wieder eine Akzentuierung elitärer Grundzüge entgegen, wenn etwa dem Komitee zur Errichtung des Denkmals für Admiral Gaspard de Coligny 1889 Mitglieder der Société de l'histoire du Protestantisme Français und der Académie

que de France aus. Vgl. Communication du comité, in: CMPV, Année 1878, S. 152. Das Denkmal für die beiden Chemiker Pelletier und Caventou vom gleichen Jahr entstand aus einer Initiative im Kreis der Société de Prévoyance des Pharmaciens und wurde von einem vor allem aus Medizinern und Pharmazeuten bestehenden Komitee, darunter Delegierten der Pharmazieschulen in neun weiteren französischen Städten betrieben. Vgl. Souscription pour élever un monument à la mémoire de Le Verrier, o. O. o. J., AN F ${ }^{21}$ I 168 Dossier ibid. S. If. Auch nicht-naturwissenschaftliche akademische Institutionen und Gesellschaften traten als Denkmalstifter auf. Die Initiative für ein im Oktober 1897 errichtetes Denkmal für Guy de Maupassant ging ebenso von der Société des gens de lettres aus wie diejenige zugunsten eines Monuments für Alphonse Daudet, das Ende Mai 1902 im Jardin des Champs Elysées eingeweiht wurde. Vgl. Brief des Präsidenten der Société an den Innenminister vom 15. Mai 1897, AN F ${ }^{21} 4860$ Dossier: Monument G. de Maupassant, 25 juin 1894-4 janvier 1898; Brief des Präsidenten der Société Abel Hermant an den Innenminister vom 19. Mai 1902, AN F ${ }^{\text {lc }}$ I 170 Dossier: 16 janvier 1902-17 mai 1902 Érection d'un monument à Alphonse Daudet. Unter der Leitung von Émile Zola war es wiederum die Société, die sich für ein Statue Honoré de Balzacs einsetzte, die im November 1902 auf der Avenue Friedland enthüllt werden konnte. Vgl. Brief des Vorsitzenden der Société des gens de lettres Emile Zola an den Innenminister vom 14. März 1892, AN F ${ }^{\text {lc }} I 169$ Dossier 14 mars-5 avril 1892 Érection d'une statue à Balzac.

${ }^{204} \mathrm{Vgl}$. auch zum Folgenden Le Temps, 19. Mai 1889, S. 2.

${ }^{205}$ Vgl. Mise au concours, séance du 9 avril 1884, in: CMPV, Année 1884, $1^{\text {er }}$ sem., S. 906f.

${ }^{206}$ Vgl. Comité pour l'érection d'une statue à Paris à F.V. Raspail, AN F ${ }^{21} 4856$ Dossier: Monument de F.V. Raspail, par le statuaire Morice, 18 juin 1888-18 juillet 1889; [An.,] La statue de Raspail. Son inauguration à Paris le 7 juillet 1889, Paris 1890, S. 6.

${ }^{207}$ Vgl. das Komitee, das unter Führung der republikanischen Ligue des droits de l'homme ein Denkmal für deren Gründer Ludovic Trarieux betrieb. Vgl. Ligue Française pour la défense des droits de l'homme et du citoyen, 2 mai 1904. Le Monument Trarieux, Paris 1904, AN F $^{21} 4857$ Dossier: Monument Trarieux par Jean Boucher, 25 juin 1906-4 juillet 1907 [up]; Comité du Monument Trarieux. Appel, ibid. 
des sciences, drei Senatoren, drei Barone und ein Graf, der Generaldirektor der Weltausstellung von 1889 Georges Berger und der französische Botschafter in London William Waddington angehörten ${ }^{208}$.

Militärisches Personal tauchte demgegenüber grundsätzlich selten bei den Denkmalstiftungen auf. So gehörten zum Komitee, das die Errichtung eines Denkmals für den Maler Ernest Meissonier betrieb, drei Generale ${ }^{209}$, ein weiterer General jeweils auch zum Komitee für das Le Verrier- ${ }^{210}$ oder das Coligny-Denkmal $^{211}$. Insgesamt selten, aber am häufigsten im Falle von Monumenten für nicht-französisches Personal standen schließlich private Donatoren im Hintergrund von Denkmalerrichtungen ${ }^{212}$.

\subsection{Berlin}

1. Bereits vor 1871 erwiesen sich Berliner Denkmalsetzungen zum Teil als dezidiert bürgerliche Unternehmungen. Die Initiative zu einem Denkmal König Friedrich Wilhelms III. im Tiergarten, das 1849 enthüllt werden konnte, ging bereits 1841 von "Bewohnern Berlins« aus, die sich am 3. August 1841 zu einem Komitee zusammengefunden hatten, den Aufstellungsort vorschlugen und Sammlungen in die Wege leiteten ${ }^{213}$. Das Komitee umfaßte »hohe Staatsbeamte und Offiziere, den Oberbürgermeister und Vertreter der städtischen Selbstverwaltung, Handwerksmeister, Buchhändler (...), den Protagonisten der Berliner metallverarbeitenden Industrie, Maschinenbaumeister Borsig und Tuchbereiter Kalckbrenner ${ }^{214}$ und markierte somit nicht nur die erste nicht-monarchische Stiftungsinitiative nach der Revolution von 1848, sondern stand auch für das Stifterprofil anderer Unternehmungen, das von hohen und

${ }^{208}$ Vgl. Bulletin historique et littéraire de la Société de l'histoire du Protestantisme Français 38 (1889) S. $55 \mathrm{f}$.

${ }^{209}$ Vgl. Comité du monument Meissonier, AN F 4853 Dossier: Monument Meissonier 22 juillet 1891-31 mars 1896 .

${ }^{210} \mathrm{Vgl}$. Souscription pour élever un monument à la mémoire de Le Verrier, o. O. o. J., AN F ${ }^{21}$ I 168 Dossier ibid. S. If.

${ }^{211}$ Vgl. Bulletin (...) de la Société de l'histoire du Protestantisme Français 38 (1889) S. $55 f$.

${ }^{212}$ So handelte es sich bei dem 1895 auf der Place des États-Unis errichteten Denkmal für Marquis de Lafayette und George Washington um eine Schenkung des New Yorker Privatmannes Joseph Pulitzer an die Stadt Paris. Vgl. Le Temps, 2. Dezember 1895, S. 2. Die Statue für Benjamin Franklin auf der Place du Trocadéro schenkte ein amerikanischer Bankier; vgl. Brief von John $\mathbf{H}$. Harjes an den leitenden Direktor der Services d'Architecture et des Promenades in Paris am 23. Mai 1905; Bulletin Municipal Officiel, 1. Mai 1906, AP VM 92/5 Dossier: Jardin du Trocadéro.

${ }^{213} \mathrm{Vgl}$. Komiteemitglieder an den König, 8. August 1841, GStA I. HA Rep. 89 Nr. 20914, Bd. 1, BI. 24. Enthalten sind nur Namen, keine Berufsbezeichnungen.

${ }^{214}$ Vgl. FADEN, Zur politischen Geschichte, S. 92. Faden datiert die Einweihung des Denkmals fälschlich auf den 9. August. 
mittleren staatlichen und städtischen Beamten, Bildungs- und in kleinerem Umfang auch Wirtschaftsbürgertum und vereinzelten Militärs bestimmt war $^{215}$.

Einen nicht nur militärischen, sondern auch eminent politischen Entstehungungskontext besaß demgegenüber die 1854 errichtete Invalidensäule. Thr Bau ging auf einen Anfang März 1849 lancierten Aufruf des Vorsitzenden eines ausschließlich aus Militärs gebildeten "Comités zur Unterstützung der Angehörigen der in Berlin, Posen, Mainz, Frankfurt und Schleswig-Holstein gebliebenen, sowie der verwundeten und vermißten Preußischen Krieger«, Christian Harkort aus Westfalen zurück, in dem ein Denkmal für die Soldaten gefordert wurde, die bei den Barrikadenkämpfen im März in Berlin getötet worden waren. $\mathrm{Da}$ der initiierende Unterstützungsverein, der sich bislang für die Versorgung von Kriegsinvaliden und hinterbliebenen Familien engagiert hatte, bereits über ein weites Aktivitäts- und Kommunikationsnetz verfügte ${ }^{216}$, mußte der Breitenwirkung des Appells zuträglich sein und verhalf ihm zu Resonanz auch in anderen preußischen Provinzen wie außerhalb Preußens ${ }^{217}$.

2. Auch nach 1871 verdankten sich zahlreiche Denkmalinitiativen dem Engagement städtisch-bürgerlicher Gruppierungen. Dies galt auch für die kleineren Dynastendenkmäler im städtischen Randbereich. Die Initiative zur Errichtung eines Denkmals für den Kurfürsten Joachim II. in Berlin-Spandau etwa ging aus den Reihen der kirchlichen Hierarchie hervor. Hier war es der Referent des Königlichen Konsistoriums der Provinz Brandenburg, der das Monument als Reminiszenz an die Einführung der Reformation in Brandenburg anregte $^{218}$. Für ein 1880 eingeweihtes Denkmal zu Ehren der Königin Luise im Tiergarten setzten sich zum einen ein $»$ Verein der Conservativen der Luisen-

${ }^{215}$ Ein bildungs- und kleinbürgerliches Festkomitee stand auch hinter dem 1858 in Oranienburg errichteten Denkmal für die preußische Königin Luise. Ein ähnliches Stifterprofil zeigt die Initiative für Beuth. Vgl. Anzeige und Subskriptionsaufruf vom 7. Oktober 1853, GStA PK I. HA Rep. 89 Nr. 20894, Bl. 2; Aufruf des Central-Komités zur Errichtung eines Monumentes für den Wirklichen Geheimen Rath Beuth vom Dezember 1853, beide GStA PK I. HA Rep. 93 B Nr. 2363, Bl. 45 Rs.; Programm für die Feierlichkeiten bei der Enthüllung des Luisen-Denkmals zu Oranienburg, ibid. Bl. 56; Brief des Magistrats der Stadt Oranienburg vom 31. März 1858 an den König, GStA PK I. HA Rep. 89 Nr. 20903, Bl. $50 f$.

${ }^{216} \mathrm{Vgl}$. den Spendenaufruf für die Belange der Invaliden- und Hinterbliebenversorgung BLHA Rep. 30 C, Nr. 2917, Bl. 9.

${ }^{217}$ Vgl. G. RAHN, Das National-Krieger-Denkmal im Invalidenpark zu Berlin, Berlin 1854, S. 5. Jenseits eines militärischen Kontextes ging über den Berliner Raum hinaus auch die Initiative zugunsten eines Anfang 1860 zustandegekommenen Denkmals für den landwirtschaftlichen Reformer Thaer. Vgl. den Bericht vom 2. März 1843, GStA PK I. HA Rep. 89 Nr. 20893, BI. 3-4.

${ }^{218}$ Vgl. Memorandum an den König vom 11. Juni 1887, GStA PK I. HA Rep. 89 Nr. 20904, Bl. 79 und NPKZ, 31. Oktober 1889, S. 3. Auch hinter dem 1902 in Rixdorf errichteten Reiterdenkmal für Wilhelm I. stand 1895 ein kommunales Komitee mit dem Bürgermeister von Rixdorf an der Spitze. Vgl. Brief des Innenministers an Wilhelm II. vom 13. Februar 1901, GStA PK ibid. Bl. 6. 
stadt von Alt-Cölln und St. Jakoby« ein, »an dessen Spitze achtbare und der conservativen Sache ergebene Personen « standen ${ }^{219}$, zum anderen eine weitere städtische Initatorengruppe ${ }^{220}$, die neben Mitgliedern von Magistrat und Stadtverordnetenversammlung auch beamtete Vertreter des gehobenen und mittleren Bildungsbürgertums, des Wirtschaftsbürgertums und der freien Berufe umfaßte ${ }^{221}$.

Auch jenseits der monarchischen Monumente dominierten wie in den Reihen der Komitees zur Errichtung eines Denkmals für Friedrich Ludwig Jahn ${ }^{222}$ 1872, für Schiller ${ }^{223} 1871$ und für Goethe ${ }^{224} 1880$ bildungs-, wirtschafts- und kleinbürgerliche Mitglieder. Von diesem Erscheinungsbild wich die Initiative für ein Lessing-Denkmal ${ }^{25}$ nur ab, weil parallel dazu, aber mit einem analogen Profil, ein ausschließlich jüdisches Denkmalkomitee entstand, das seine

${ }^{219}$ Vgl. Bericht des Kultusministers Falk an Wilhelm I. vom 20. Dezember 1875, GStA PK I. HA Rep. 89 Nr. 20903, Bl. 119.

${ }^{220}$ Vgl. Bericht vom 14. April 1880, ibid. Bl. 205-207, hier Bl. 205f. und Communal-Blatt, 1. April 1877, LAB A Rep. 000-02-01 Nr. 2381 [up].

${ }^{221}$ Vgl. Communal-Blatt, 16. April 1876, LAB A Rep. 000-02-01 Nr. 2831. Dazu zählten vier Universitätsprofessoren (darunter Mommsen), acht (Geheime) Kommerzienräte, drei Geheime Regierungsräte, ein Oberkonsistorialrat, ein Generalsuperintendent, ein Stadtgerichtsrat, der Direktor eines Gymnasiums, zwei Distriktvorsteher, der Königliche Gartendirektor, ein Schriftsteller, zwei Chefredakteure, der Direktor der Akademie der Künste Anton von Werner, ein Hof-Buchhändler, ein Bankier, zwei Rentiers, der Unternehmer Werner Siemens und ein Civil-Ingenieur. Dem Komitee zur Errichtung eines Denkmals für Kaiserin Augusta unter der Leitung des Berliner Oberbürgermeisters von Forckenbeck gehörten auch mehrere Militärs (drei Generale der Infanterie, zwei Generalleutenante z.D., ein Oberst z.D., ein General der Kavallerie z.D., ein Oberstleutnant a.D., ein Generalmajor) und ein katholischer Geistlicher an. Vgl. Aufruf zur Errichtung eines Denkmals weiland Ihrer Majestät der Kaiserin-Königin Augusta vom 7. Januar 1891, LAB A Rep. 00002-01 Nr. 1631, Bl. 101 und GStA PK I. HA Rep. 89 Nr. 20904, Bl. 214.

${ }^{222} \mathrm{VZ}, 11$. August 1872, 4. Beilage, S. 1-2, hier S. 2. Vgl. Dieter DUDNG, Organisierter gesellschaftlicher Nationalismus in Deutschland (1808-1847). Bedeutung und Funktion der Turner- und Sängervereine für die deutsche Nationalbewegung, München 1984 (Studien zur Geschichte des 19. Jahrhunderts, 13), S. 76-78; Aufruf zu Sammlungen für ein Denkmal des Turnvaters Friedrich Ludwig Jahn in Berlin, 18. Juni 1861, GStA PK I. HA Rep. 89 Nr. 20835, Bl. 107-108, hier Bl. 108 Rs.

${ }^{223} \mathrm{Vgl}$. Der Beobachter an der Spree, 12. November 1871, in: [An.,] Schiller-Denkmal Berlin 1871, Bd. 1, Bl. 4.

${ }^{224} \mathrm{Vgl}$. [An.,] Zwei Actenstücke betreffend die Errichtung eines Denkmals für Goethe in Berlin nebst unmassgeblichen Vorschlägen für die Vertheilung der einzelnen Mitglieder des Comités in vier Abtheilungen und einen leitenden Ausschuss, Berlin 1860, S. 3-6.

${ }^{225} \mathrm{Vgl}$. Einladung an die Mitglieder des Schiller- und des Goethe-Comité (...), in: [Ausschuß des Lessing-Comités,] Aktenstücke und Beläge, die am 6. November 1861 Allerhöchst genehmigte Vereinigung der Standbilder Lessing's, Schiller's und Goethe's vor dem königlichen Schauspielhause zu Berlin betreffend (Vom Anfange 1861 bis 12. November 1867). Im Auftrage des Lessing-Comité, Berlin ${ }^{2} 1870$, S. 8-9, hier S. 9; Immediat-Eingabe an Se. Majestät den König, 24. Juli 1861, in: ibid. S. 21-22, hier S. 22; Offentlicher Aufruf zur Errichtung des Lessing-Standbildes in Berlin, 10. Januar 1862, ibid. S. 39-41, hier S. 4041. 
Initiative ausdrücklich nicht mit dem Willen zur »Absonderung«, sondern mit einer besonderen Verpflichtung der »Juden« gegenüber Lessings ToleranzErbe begründete ${ }^{226}$. Auch das 1890 konstituierte Komitee zur Errichtung eines Bismarck-Monuments entsprach der gängigen Praxis, zeichnete sich aber zum einen dadurch aus, daß Reichstagsmitglieder und Minister dominierten, zum anderen ein vergrößerter Partizipationsradius erreicht wurde, indem seine Mitglieder nicht nur aus Berlin, sondern auch aus Köln, Hamburg, Düsseldorf, Augsburg und Frankfurt ${ }^{227}$ stammten $^{228}$. Von den landesweit errichteten Bismarckdenkmälern hob es sich insofern ab, als in Berlin nun zum einen nicht wie andernorts eher kleinbürgerliche Stifter dominierten und zum anderen auch ein preußisch-etatistischer Entstehungszusammenhang dominant war, der den reichsweiten Initiativen häufig fehlte ${ }^{229}$. Schließlich trat, auch dies gemessen am reichsweiten Bismarckkult ungewöhnlich, Wilhelm II. als »Protector« an die Spitze des Berliner Unternehmens ${ }^{230}$.

${ }^{226}$ Vgl. Aufruf an die jüdischen Verehrer Lessings, Februar 1862, ibid. S. 42-3; Vossische Zeitung, 2. November 1880 (1. Beilage), S. 3. Das Stifterprofil im Umkeis des 1895 eingeweihten Luther-Denkmals variierte ebenfalls nur durch eine einschlägig konfessionellkirchliche Prägung, indem nun höherrangige Vertreter der protestantischen Kirche in Gestalt eines Konsistorialrats, dreier Generalsuperintendenten und eines Predigers das Erscheinungsbild prägten. Vgl. Aufruf für das auf dem Neuen Markt in Berlin zu errichtende Luther-Denkmal, GStA PK I. HA Rep. 89 Nr. 20887, Bl. 42.

${ }^{227} \mathrm{Vgl}$. Brief des provisorischen Komitees an Wilhelm II. vom 1. April 1890, GStA PK ibid. Bl. 10-13 Rs.

${ }^{228}$ Eine erste Initiative zu einem Bismarck-Denkmal gab es längst zu Lebzeiten des Kanzlers. 1884 erbot sich ein Kaufmann Rudolph Hertzog beim Kaiser, mit einer Million Mark in Vorleistung für ein Bismarckmonument zu gehen, dessen Konzept und Standort der Monarch bestimmen sollte. Zu Zeiten Wilhelms I. blieb das Ansinnen unberücksichtigt. Vgl. Schreiben Rudolph Hertzogs an Wilhelm I. vom 6. April 1884, GStA PK I. HA Rep. 89 Nr. 20896, Bl. 4.

${ }^{229}$ Vgl. dazu HARDTWIG, Erinnerung, Wissenschaft, Mythos, S. 249f. und HEDINGER, Bismarck-Denkmäler, $S$. 282f.

${ }^{230} \mathrm{Vgl}$. Brief des Kabinettsrats von Lucanus an das provisorische Komitee vom 9. April 1890, GStA PK ibid. Bl. 15. Dies galt auch für den Verein, der die "Bismarck-Warte« 1900 betrieb; vgl. RENISCH, Überblick über die Geschichte des Vereins »Bismarck-Warte« während seines fünfjährigen Bestehens 1899-1904 mit besonderer Berücksichtigung der Grundsteinlegung und Einweihung der Bismarck-Warte auf den Müggelbergen, Coepenick 1904, S. 8. Über die Berliner Komitees um die Roon- und Moltkedenkmäler liegen eher spärliche Informationen vor. An der Spitze des im Sommer 1901 gebildeten RoonKomitees stand der dafür eigens angeworbene Regent des Herzogtums Braunschweig Prinz Albrecht von Preußen. Im geschäftsführenden Ausschuß beteiligten sich Reichskanzler von Bülow, der preußische Kriegsminister von Goßler und der Präsident der Seehandlung $\mathrm{Ha}$ venstein. Vgl. Zusage des Prinzen vom 28. April 1901, BArch R 43/2388, Bl. 15 und Roon-Denkmal! Unter dem Protektorate Seiner Königlichen Hoheit des Prinzen Albrecht von Preußen, GStA PK I. HA Rep. 89 Nr. 20838, Bl. 43; Schreiben des geschäftsführenden Ausschusses vom 8. November 1901, GStA PK I. HA Rep. 93 B Nr. 2366, Bl. 4. Das um 1904/05 vor dem Generalstabsgebäude plazierte Denkmal für Moltke ging auf die Initiative von Mitgliedern des nationalliberalen Wahlvereins von Breslau um den Prokuristen 
Gelegentlich gingen Initiativen aus den Reihen von Berufsverbänden hervor, wenn sich etwa die Stifter eines Werner von Siemens-Denkmals aus dem Berliner Bezirksverein deutscher Ingenieure rekrutierten ${ }^{231}$. Mitunter traten an der Grenze zwischen akademischen Wissenschaftsinstitutionen und Politik Vernetzungseffekte zwischen renommierten Stiftern auf, die in mehreren Komitees vertreten waren und am Ende zum Teil selbst Denkmäler erhielten. Dieses Phänomen ergab sich etwa, als im Mai 1859 und nach einem ersten Fehlschlag erneut zehn Jahre später mit ähnlichem Komiteeprofil eine Initiative zur Errichtung eines Monuments für den Forscher Alexander von Humboldt von dem Pathologen und liberalen Abgeordneten Rudolf Virchow an der Spitze einer Gruppe von 31 Kollegen und Freunden ausging ${ }^{232}$. Der Kern der Initiatorengruppe um Virchow, von Siemens, Helmholtz und den Physiologen Emil Du Bois Reymond fand hier nicht neu um den Anlaß der Denkmalerrichtung zusammen, sondern war längst vorher über Mitgliedschaften im Preußischen Landtag ${ }^{233}$, in der Berliner Physikalischen Gesellschaft und der Königlichen Akademie der Wissenschaften ${ }^{234}$ eng sozial vernetzt ${ }^{235}$. Helmholtz' Denkmal

Wilhelm Bauer zurück. Bauer war 1860 geboren, evangelisch und Sohn eines Fabrikbesitzers und Hoflieferanten, vgl. Mitteilung des Regierungspräsidenten Ernst von Heydebrand u.d. Lasa an von Lucanus am 19. Oktober 1899, GStA PK I. HA Rep. 89 Nr. 20837, Bl. 273; Bauer an Kabinettschef von Lucanus am 22. Mai 1897, GStA PK, ibid. Bl. 141.

${ }^{231}$ Vgl. National-Zeitung, 19. Oktober 1899 (A.), S. 2. Ähnlich brachte der Verein deutscher Eisenhüttenleute und der nordwestlichen Gruppe des Vereins deutscher Eisen- und Stahlindustrieller das Denkmal für den Schwerindustriellen Alfred Krupp auf den Weg; vgl. ibid.

${ }^{232} \mathrm{Vgl}$. An das Hohe Zollparlament, Petition vom 16. Juni 1869, zit. nach: DU BOISREYMOND, Die Humboldt-Denkmäler, S. 109-110. Die Petition unterzeichneten u. a. die Botaniker Alexander Braun und Nathanael Pfringsheim, der Naturforscher von Dachröden, der Anatom und Physiologe Karl Bogislaus Reichert, der Verleger Georg Reimer und der Mineraloge Gustav Rose. Nach einem ersten Fehlschlag lancierte Virchow erneut eine Komiteegründung mit einem ähnlichen Profil. Vgl. Sitzung des Zoll-Parlaments vom 21. Juni 1869, in: Stenographische Berichte über die Verhandlungen des Deutschen Zollparlaments, Berlin 1869/70, S. 245-246, hier S. 245; An das deutsche Volk!, Subkriptionsaufruf vom 2. Juli 1869, GStA PK I. HA Rep. 89 Nr. 20835, BI. 188.

${ }^{233}$ Vgl. Helmut RECHENBERG, Persönlichkeiten aus der Frühgeschichte der PhysikalischTechnischen Reichsanstalt: Werner von Siemens, Hermann von Helmholtz, Friedrich Kohlrausch und Emil Warburg, in: Wilhelm TREUE, Gerhard HILDEBRANDT (Hg.), Berlinische Lebensbilder. Naturwissenschaftler (Einzelveröffentlichungen der Historischen Kommission zu Berlin, 60), Berlin 1987, S 45-60, hier S. 47.

${ }^{234}$ Vgl. Klaus WENG, Rudolf Virchow und Emil du Bois-Reymond. Briefe 1864-1894, Marburg/Lahn 1995, S. 50-54; DERS., Rudolf Virchow und die Humboldt-Denkmäler vor der Berliner Universität, Berlin 1995 (Berlin-Brandenburgische Akademie der Wissenschaften. Wissenschaftshistorische Manuskripte, 4), S. 5-6.

${ }^{235}$ Vgl. ibid. S. 56. 
kam allerdings nicht im Rahmen dieses Netzwerks, sondern durch kaiserliche Stiftung zustande ${ }^{236}$.

Auch die Monumente für renommierte Linksliberale, die gegen Jahrhundertende verwirklicht werden konnten, wiesen kein anderes Stifterprofil auf. Das Komitee, das sich mit dem Ziel einer öffentlichen Denkmalerrichtung für den Mitbegründer des Deutschen Nationalvereins und der Deutschen Fortschrittspartei Hermann Schulze-Delitzsch Anfang der 1860er Jahre konstituierte, unterschied sich vom Gros üblicher Initiatorenkreise kaum; besonders erschien nur die starke Präsenz von Verbandsdirektoren genossenschaftlicher Vereine und zwei Vorstandsmitgliedern des Berliner Arbeitervereins. Ungewöhnlich blieb demgegenüber die regionale Reichweite der Mitgliedschaften, indem neben einer Überzahl Berliner Komiteemitglieder hier nun Vertreter aus allen deutschen Staaten vertreten waren ${ }^{237}$. Das Denkmal für den linksliberalen Fortschritts-Politiker Franz B. L. Waldeck kam auf Betreiben des Berliner Arbeitervereins und der Mitglieder der traditionsreichen linksliberalen HirschDunckerschen Gewerkvereine zustande ${ }^{238}$. Über eine vage angedeutete soziale Öffnung nach unten kamen damit auch die Initiatoren der dezidiert linksliberalen Denkmäler nicht hinaus.

\subsection{London}

1. In London prägte früher als in den beiden Vergleichsstädten ein erstes Großprojekt schon die erste Phase des Betrachtungszeitraums. Das in den 1840er Jahren sukzessive abgeschlossene Nelson-Monument auf Trafalgar Square betrieb ein Nelson Memorial Committee mit sieben Admirälen, $13 \mathrm{Ka}$ pitänen und einem Leutnant. Sobald man per Rundbrief ${ }^{239}$ Mitinitiatoren anwarb, weitete sich der Kreis auch nach der zivilen Seite hin, blieb allerdings sozial weithin elitär. Dem Komitee gehörten bis zum Sommer 1838 über 50 Adlige an, darunter 22 Oberhausmitglieder, weiter 14 Unterhausmitglieder und diverse Militärs einschließlich des Duke of Wellington ${ }^{240}$. Ein ebenso militäri-

${ }^{236}$ Vgl. Bericht von Delbrücks vom 15. Dezember 1894, GStA PK I. HA Rep. 89 Nr. 20837, Bl. 87 und Aufruf zur Errichtung eines Denkmals von Helmholtz, 11. März 1895, GStA PK I. HA Rep. 89 Nr. 20837, Bl. 99-99 Rs.

${ }^{237}$ Vgl. Subskriptionsaufruf des Comités zur Errichtung eines Denkmals für SchulzeDelitzsch, GStA PK I. HA Rep. 89 Nr. 20837, Bl. 11-12 Rs. Generell dominierten hier Mitglieder des Reichtags und des preußischen Abgeordnetenhauses, daneben höhere $\mathrm{Be}$ amte und freie Berufe.

${ }^{238}$ Vgl. Schreiben des Vorsitzenden des Berliner Arbeitervereins an die Stadtverordnetenversammlung von Berlin am 8. Februar 1890, LAB A Rep. 000-02-01 Nr. 1634, Bl. 203.

${ }^{239}$ Vgl. Nelson Memorial Committee. Minute Book 1838-1844, PRO Work 6/1 19, Meeting 22 February 1838.

${ }^{240} \mathrm{Vgl}$. Report from the Select Committee on Trafalgar Square; together with the evidence taken before them and Appendix, 27. Juli 1840, in: HoC Parliamentary Papers Bd. 12 
sches wie vor allem parlamentarisch geweitetes Initiatorenprofil zeichnete sich auch hinter dem Ende 1867 aufgestellten Monument für Kriegsminister Lord Sidney Herbert $a^{241}$. Als unmittelbares Parallelunterfangen zum Pariser Larrey-Denkmal erwies sich nicht nur der Programmatik, sondern auch dem Initiativkontext nach das Denkmal für den Militärarzt James McGrigor, zu dessen Errichtung sich um 1861 ein Memorial Committe aus den Reihen des Royal Army Medical Corps an der Schnittstelle zwischen medizinischen und militärischen Gruppen gebildet hatte ${ }^{242}$. Über ein transnationales Initiatorenprofil verfügten demgegenüber wie etwa im Falle der Initiative für eine Statue des Mediziners Edward Jenner ${ }^{243}$ ausschließlich Stiftergruppen, die renommierte Wissenschaftler ehrten. Schließlich traten bereits 1850 erstmals auch Vertreter der City als Initiatoren auf und engagierten sich für eine monumentale Würdigung des Premierministers Robert Peel ${ }^{244}$.

2. Zahlreiche der in und nach den 1870er Jahren zustandegekommenen Londoner Denkmalprojekte fußten auf dezidiert politischen Zusammenschlüssen. So gehörten dem Komitee zur Errichtung eines Denkmals für Lord Derby, das 1874 auf dem Parliament Square aufgestellt werden konnte, vor allem politische Weggefährten und Freunde des konservativen Premiers $a^{245}$. Daneben

(1840). Reports from the Committees (Metropolis Improvements), $\mathrm{N}^{\circ} 548, \mathrm{I}-40$, hier S. 32-33

${ }^{241} \mathrm{Zu}$ den Unterstützern des Projekts zählten zunächst neben drei Generalen weitere sieben Generalleutenante, zehn Generalmajore, zwei Colonels, der Generaldirektor des Militärkrankenhauses und ein Militärgeistlicher. Beteiligt waren dann aber auch knapp 40 Unterhausmitglieder, darunter die Liberalen Palmerston und Russell und der Lord Mayor von London, sowie 16 Oberhausmitglieder. Vgl. Memorial to the late Lord Herbert. Report of the proceedings at the public meeting held at Willi's Rooms, King Street, St. James's on Thursday $28^{\text {th }}$ November 1861 . His Royal Highness the Duke of Cambridge, K.G. in the Chair, London 1862, S. 4-6.

${ }^{242} \mathrm{Vgl}$. Schreiben des Komitees an das Office of Works am 25. Januar 1861, PRO Work 20/29. Vgl. zum Larrey-Denkmal bereits Kapitel III.2.1.

${ }^{243}$ Vgl. Brief des Chairman des Komitees, John Conolly, an das Office of Works, 12. August 1857, PRO Works 20/33.

${ }^{244}$ Das Komitee bestand dann aus einem Mitglied des Repräsentationsorgans der City (Alderman), einem Geistlichen, mehreren Parlamentsmitgliedern, dem Chairman der East India Company, dem Deputy-Governor der Bank of England und Bürgern der Stadt. Vgl. The Daily Telegraph, 23. Juli 1855, S. 2; The Times, 14. November 1853, S. 10. Prominent beteiligt waren Repräsentanten der City auch am Zustandekommen eines ersten Denkmals für den Prince Consort Albert 1863. Vgl. The Art Journal 5 (1853) S. 298; The Times, 28. Oktober 1853, S. 7, 2. November 1853 , S. 8; ibid. 8. November 1853, S. 5

${ }^{245}$ An Parlamentsabgeordneten zählten dazu neben Disraeli überwiegend Konservative, darunter der spätere Lord Mayor Robert N. Fowler, der Liberal-Conservative und spätere First Commissioner of Works Lord Henry Lennox, drei Colonels und ein Captain; dazu kamen ein Duke, sechs Earls, ein Sir, acht Lords, ein Marquis, sowie 10 weitere, titellose Mitglieder. Vgl. The Times, 14. Dezember 1869, S. 4. Ein dominant konservatives Profil prägte auch die Initiatorengruppe um das Denkmal für den Tory Sir Robert Peel. Vgl. The Peel Statue - Resolution, HoC, 25. Juni 1868, in: Hansard $3^{\text {rd }}$ s., Bd. 192 (1868) Sp. 
kamen aber auch politisch vergleichsweise aufgelockerte Stifterkonstellationen zustande, wenn etwa ein Komitee zur Ehrung des liberalen Begründers des obligatorischen Grundschulsystems in Großbritannien, W. E. Forster, Mitte der 1880 er Jahre ebenso liberale wie konservative Parlamentarier umfaßte ${ }^{246}$. Ebenso fanden sich 1898 Liberale wie Konservative zur Beteiligung an einer Denkmalinitiative zugunsten Premierministers Gladstone bereit ${ }^{247}$. Singulär blieb demgegenüber, daß sich im Zusammenhang mit dem Plan eines Monuments für den Expeditionsforscher James Cook vor dem Ersten Weltkrieg ein politisch rechtslastiges Komitee konstituierte, dem sich mehrere Mitglieder der aktivistischen imperialen, dem Sozialprofil nach vor allem im Bereich der "middle class« einzuordnenden und politisch elitär zusammengesetzten British Empire League anschlossen ${ }^{248}$.

Auch im Hintergrund der Denkmalerrichtungen für Militärs standen ebenso militärisch wie zivil geprägte Stifterkreise. So gehörten zum Denkmalkomitee für General James Outram neben hochrangigen Veteranen und Offizieren auch zwei Literaten, ein Vertreter der Metropole, ein konservativer und ein liberaler Parlamentarier ${ }^{249}$. In einigen Fällen zeichnete sich dabei ein Zusammenspiel mit der City ab, wenn etwa die Initiative zur Errichtung eines Denkmals für den $1885 \mathrm{im}$ Sudan gefallenen General Gordon auf ein unter Leitung des Lord Mayors von London und des Prince of Wales gegründetes "Mansion House Committee « zurückging ${ }^{250}$, das darüber hinaus eine renommierte Teilnehmerliste vorzuweisen hatte, auf der sich der anglikanische Erzbischof von Canterbury ebenso eingetragen hatte wie der ultramontane Kardinal Henry E. Manning und der konservative Premier Lord Salisbury ${ }^{251}$. Überhaupt engagierten sich

2138-2150, hier Sp. 2143; Lord Cardwell an den First Commissioner of Works Cowper, 25. Mai 1863, PRO Work 20/31 [up].

${ }^{246} \mathrm{Vgl}$. The Times, 2. August 1890, S. 5; Sitzung des MBW vom 29. Juli 1887, in: Minutes of Proceedings of the MBW Juli-Dezember 1887, 207/70 und MBW Presented Papers 604 , Bd. 388, Nr. 70.

${ }^{247}$ Vgl. The Manchester Guardian, 4. November 1905, S. 7. Im Komitee vertreten waren der Liberale und langjährige Kolonialminister Lord Kimberley oder Sir Jospeh Pease ebenso wie der Konservative und Unionist Lord Curzon.

${ }^{248}$ Vgl. The Times, 29. Juni 1914, S. 5; ibid. 8. Juli 1914, S. 10. Vgl. John M. MACKENZE, Propaganda and Empire, S. 151-152. Vgl. u. a. Brief an Frank Baines vom 2. Juli 1914, PRO Work 20/79 [up]. Kirchliche Initiatorengnuppen waren demgegenüber stärker unter den Stiftern der 1884 eingeweihten Statue für den englischen Reformer Tyndale vertreten. An der Spitze des Komitees, dem weitere, darunter hochrangige Geistliche wie der Erzbischof von Canterbury und mehrere Mitglieder der British and Foreign Bible Society angehörten, stand der anglikanische Geistliche Dean Stanley. Vgl. MBW, Presented papers 496, Bd. 280, Nr. 39; The Times, 26. April 1879, S. 11; ibid. 26. Juni 1879, S. 7; ibid. 3. April 1882, S. 8.

${ }^{249} \mathrm{Vgl}$. [An.,] Outram Testimonial, London 1861, S. 21.

${ }^{250} \mathrm{Vgl}$. ibid. Ähnliche Konstellationen prägen die Initiative für das Denkmal zur Erinnerung an Feldmarschall Robert C. Napier; vgl. The Morning Post, 9. Juli 1891, S. 2.

251 Vgl. The Times, 3. März 1885, S. 8. 
regelmäßig Mitglieder der königlichen Familie für die Denkmalwürdigung von militärischem Personal ${ }^{252}$. Dagegen blieben Schenkungen wie im Falle eines der Prince Consort-Denkmäler, das im Januar 1874 ein anonymer Privatier der Stadt überlie ${ }^{253}$, und des Denkmals für den schottischen Literaten Robert Burns, das 1884 der schottische Kaufmann John Gordon Crawford initiierte ${ }^{254}$, eher selten.

Nicht anders als in Berlin kamen Monarchendenkmäler in London nicht nur aufgrund monarchischer, sondern auch privater oder städtischer Initiativen zustande. Am Jubilee Memorial Committee, das sich Anfang der 1890er Jahre um die Errichtung eines Denkmals für Queen Victoria nahe des Kensington Palace bemühte ${ }^{255}$, beteiligten sich erneut v.a. konservative und liberale Parlamentarier neben mehreren hochrangigen Militärs. Außergewöhnlich und symptomatisch für das politische Prestige der Geehrten nahm sich hier jedoch die Teilnahme auswärtiger Politiker wie des ehemaligen kanadischen Premiers Sir Charles Tupper und des südafrikanischen Staatsmannes John J. Merriman $\operatorname{aus}^{256}$.

${ }^{252}$ So gehörten dem Komitee, das sich Mitte der 1890er Jahre um ein Reiterdenkmal zugunsten des Feldherrn Sir Hugh Rose, Baron Strathnairn, bemühte, Mitglieder der königlichen Familie und des Militärs an. Vgl. The Daily Telegraph, 20. Juni 1895, S. 4; The Morning Post, 20. Juni 1895, S. 2. Ebenso trat der Prince of Wales als Vorsitzender eines Exekutivkomitees zur Errichtung eines Denkmals fur den Kolonialpolitiker und Gouverneur Sir Bartle Frere auf. Vgl. Sitzung des MBW am 11. Juli 1884, in: Minutes of the Proceedings of the MBW Juli-Dezember 1884, 89/47; Sitzung vom 7. Januar 1887, in: ibid. JanuarJuni 1887, 16/33; The Times, 6. Juni 1888, S. 12. Eine entsprechende Protektorenrolle blieb nicht auf militärisches Personal beschränkt. Etwa konnte man auch als Vorsitzenden des Generalkomitees zur Errichtung des Gladstone-Denkmals den Prince of Wales und späteren König Edward VII. gewinnen. Vgl. The Manchester Guardian, 4. November 1905, S. 7.

${ }^{253} \mathrm{Vgl}$. Description of the Equestrian Statue of the Prince Consort erected in Holborn Circus and to be unveiled in the presence of His Royal Highness the Prince of Wales on Friday $9^{\text {th }}$ January 1874, London 1874, CLRO, Papers relating to the Prince Consort Memorial, Holborn Circus c. 1872-1874, Holborn Valley Box 9.8 [up].

${ }^{254} \mathrm{Vgl}$. Sitzung des MBW vom 1. Dezember 1882, in: Minutes of Proceedings of the MBW Juli-Dezember 1882, 845/29; MBW Presented Papers 550, Bd. 334, S. 29; Sitzung des MBW vom 30. Mai 1884, in: Minutes of Proceedings of the MBW Januar-Juni 1884, $918 / 53$ u.o.

${ }^{255} \mathrm{Vgl}$. The Daily Telegraph, 29. Juni 1893, S. 5.

${ }^{256} \mathrm{Vgl}$. The Morning Post, 29. Juli 1893, S. 5; Notiz aus dem Office of Works vom 25. Juni 1893, PRO Work 20/77 [up]. So war es auch die Londoner City of London Corporation, die sich für die Überarbeitung und Neuaufstellung der Queen Anne-Statue 1886 vor der St.Paul's-Kathedrale einsetzte. Vgl. The Times, 16. Dezember 1886, S. 10; Metropolis Queen Anne's Statue, St.Paul's Churchyard, Sitzung des HoC vom 2. August 1875, Hansard Bd. 226 (1875) Sp. 371; The Times, 16. Dezember 1886, S. 10. Bei den übrigen Initiativen für Monarchendenkmäler dominierten demgegenüber deutlich lokalere Stifterkreise. Dies gilt für das Queen Victoria-Denkmal, das 1904 im Londoner Stadtteil Kensington entstand ebenso, wie für das Queen Alexandra-Denkmal im Innenhof des London Hospital im East-End von 1908 und die im Borough von Wandsworth entstandene Initiative für ein 
Eine seltene Öffnung für weibliches Personal trat schließlich im Falle der Denkmalstiftung für John Stuart Mill 1878 auf, indem dem entsprechenden Komitee unter den Publizisten, Autoren, Sozialreformern und Akademikern vereinzelt auch Frauen angehörten ${ }^{257}$. Entsprechende Inklusionsphänomene blieben allerdings weithin Episode.

\section{Vergleich}

Die administrative und kompetenzrechtliche Infrastruktur in den drei Hauptstädten hat in der Regel der staatlichen Autorität ein Höchstmaß an Handlungsspielraum und Interventionsrechten gewährt. Der französische Staatspräsident bzw. Innenminister und Préfet de la Seine, der preußisch-deutsche Monarch und meist auch das königliche Office of Works fungierten regelmäBig als Letztinstanzen. Die britische Monarchie hat unterdessen jedenfalls über den größten Teil des Betrachtungszeitraums hinweg nicht auch nur annähernd so viel Interesse an symbolpolitischen Akten gezeigt, wie dies zur gleichen Zeit bei den preußischen Regenten erkennbar war. Entsprechend selten intervenierten britische Monarchen in bereits laufende Projekte. Jedoch hat das Office of Works direkt oder durch die nachträgliche Übernahme von Denkmälern in seinen Verfügungsbereich durchaus auch Symbolkontrolle betrieben, die freilich weniger insistierend als in Berlin durchgeführt worden ist. Darüber hinaus haben in London die städtischen Gremien infolge des parochialen Föderalismus tendenziell mehr als in Berlin und Paris Entscheidungskompetenz behalten. Es zeichnete sich aber nicht $a b$, daß deshalb in nennenswert stärkerem Maße als dort das städtische Terrain zur Aufstellung privater oder städtischer Denkmäler genutzt worden wäre.

Der Conseil Municipal von Paris hat verglichen mit der Berliner Stadtverordnetenversammlung eine deutlich aktivere Rolle im öffentlichen Denkmalbau gespielt. Von Vorteil war hier der Umstand, daß sich anders als in

Edward VII.-Denkmal 1911. Vgl. Kensington Local Memorial to her late Majesty Queen Victoria, Kensington Local Studies Central Library, 731.76 Vic. 518; zum AlexandraDenkmal vgl. The Daily Telegraph, 11. Juli 1908, S. 6, zum Edward VII.-Denkmal The Standard, 6. November 1911, S. 4.

${ }^{257}$ Neben dem Whig-Minister George D. Campell, Duke of Argyll, dem Herausgeber des The Economist Walter Bagehot, dem Sozialreformer Edwin Chadwick, dem langjährigen Radical MP für Chelsea und politischen Freund des französischen Republikaners Gambetta, Charles Dilke, dem Liberalen Henry Fawcett, dem liberalen irischen Historiker und Essayisten William E.H. Lecky, dem Philosophen Herbert Spencer, mehreren namhaften Wissenschaftlem und Arthur Arnold vom Reform Club, der Keimzelle der liberalen Partei, waren dies die Philantropin und Literatin Frances P. Cobbe, und die in der Frauenrechtsbewegung prominent engagierte Millicent Fawcett. Vgl. The Daily Telegraph, 28. Januar 1878, S. 3 . 
Berlin nicht ein fortschrittlich-linkes städtisches Gremium und eine autoritärkonservative Staatsautorität, sondern auf städtischer wie staatlicher Seite Akteure freilich unterschiedlicher republikanischer Couleur gegenüberstanden. In dieser Konstellation lagen ebenso Chancen zu mehr Konvergenz wie umgekehrt auch Auslöser für symbolpolitische Profilierungsakte eines tendenziell von der radikalen Linken dominierten Conseil gegenüber den moderateren Regierungskräften. Mit der Zunahme und Vertiefung innerrepublikanischer Binnendifferenzen und der Intensität öffentlicher Symbolpolitik konnte hier das Kollisionspotential durchaus steigen - und hat dies, wie im Vorgriff zu sagen ist, auch in erheblichem Maße getan. Dem Kompetenzarrangement nach allerdings zeichnete sich dies zunächst nicht $a b$.

Der Zugriff der preußisch-deutschen Monarchen auf die öffentliche Symbollandschaft wurde demgegenüber früher und deutlich rigider geübt und bezog sich weit über die Monarchendenkmäler hinaus auch auf die Statuen von Militärs oder zivilen Bürgern. Die monarchische Reglementierung erfolgte dabei nicht nur in Gestalt beträchtlicher Obstruktion, wie sie sich im Blick auf die Denkmäler für die Linksliberalen abzeichnete. Sie schlug sich auch bereits mehr oder minder latent in der schleichenden Involvierung und schließlich Überformung bereits laufender Projekte nieder. Vergleichbare Phänomene sind zwar sowohl in Paris als auch in London aufgetreten, blieben dort aber vergleichsweise singulär. Zwar konnte die Stadtverordnetenversammlung unter diesen Bedingungen nicht die Rolle eines wahrnehmbar eigenständigen Akteurs spielen. Private, auf akademische, professionelle, soziale und politische Vernetzungen aufbauende Denkmalinitiativen, an denen sich namhafte Repräsentanten des Gremiums je neu beteiligten, sind dessen ungeachtet genauso wie in den beiden Vergleichsfällen zu beobachten.

Der Umstand, daß in London und z.T. Paris anders als in Berlin Berufsangaben und damit soziale Statusmarkierungen auf den Mitgliederlisten der Vereine oder lockeren Gruppierungen häufig fehlten, ist im Blick auf die Initiatorenprofile bereits ein erster Befund. Er legt nahe, daß die symbolische Einbindung in das Unternehmen nationaler Konsensbekundung, als das sich die Denkmalinitiativen subjektiv verstanden, in Berlin mehr als in den europäischen Hauptstädten unter dem Vorzeichen sozialer Statusdifferenzierung vonstatten ging. Mit der Ausblendung von Berufsangaben auf den Mitgliederlisten französischer und englischer Komitees schien demgegenüber das Kriterium sozialer Ungleichheit programmatisch und im Sinne der nationalen Homogenitätsfiktion übergangen worden zu sein. Unelitärer oder bemerkenswert inklusiver stellten sich, sofern sie näherungsweise ausgemacht werden können, die Initiatorenprofile in Paris oder London deshalb aber keineswegs dar. Unterbürgerliche Gruppierungen und Frauen blieben jedenfalls mit wenigen Ausnahmen weithin konsequent ausgegrenzt, während in Paris am ehesten, aber 
nach wie vor selten, Aufweichungen zugunsten kleinbürgerlicher Formationen auftraten.

Generell entstanden die meisten Denkmäler in den drei Städten durch die Konstituierung von Komitees, die ausschließlich auf die Aufgabe und Planung der jeweiligen Denkmalsetzung fixiert waren, dabei aber berufliche, akademische und politische Vernetzungen aktivierten, um Mitglieder anzuwerben. Im Vorfeld von Denkmalerrichtungen für Wissenschaftler und Forscher hingegen gingen entsprechende Initiativen oftmals aus dem institutionellen Kontext bereits etablierter, in der Regel akademisch elitärer Institutionen und Vereinigungen hervor, die neben ihrer professionellen Arbeit nun auch die Monumentalisierung organisierten. Hier bestand auch am ehesten die Chance, daß solche Netzwerke sich deutlich außerhalb der hauptstädtischen oder der gesamtstaatlichen Reichweite bewegten und sogar internationale Initiatorenkreise entstanden.

In allen Städten dominierten Parlamentarier und ministerielle Amtsträger die Initiatorengruppen, mit deren Namhaftigkeit in der Regel zugleich das Prestige der Projekte stieg; die Parlamentsnähe wurde damit zu einem beherrschenden Signum hauptstädtischer Stifterprofile. Von einer defizitären Rolle des deutschen Bürgertums im Rahmen der Denkmalunternehmungen kann daher angesichts evidenter und dominanter Staatsnähe auch englischer und französischer Stiftergruppen nicht gesprochen werden. Militärische Profile kamen demgegenüber nicht in Berlin, sondern tendenziell am ehesten in London zustande, erwiesen sich hier aber regelmäßig als durchaus kompatibel mit den gängigen zivilen und politischen Komiteemitgliedern. Stärker als in London und Berlin sind darüber hinaus in Paris Journalisten der republikanischen Presse zumindest als Mitinitiatoren aufgetreten. Hierin, wie in der besonders intensiven Aufmerksamkeit, die das Thema öffentlicher Denkmalerrichtungen in der veröffentlichten Meinung Frankreichs erreichte, waren sie zugleich ein Symptom für früh geschärfte und sensibilisierte Blicke einer politisierten publizierenden Öffentlichkeit auf Fragen monumentaler und national konnotierter Deutungsmacht im städtischen Raum.

Damit dominierten letztlich in Berlin staatsnahe (bildungs)bürgerliche Formationen als Hauptakteure der Denkmalunternehmungen, die sich gegenüber unterbürgerlichen Gruppen abschlossen und die national konnotierte Geste der Denkmalsetzung insofern auch als Bestandteil ihres Status erachteten. Alle Kennzeichen einer politischen, in der Regel aber nicht-adligen, großbürgerlichen Eliten-Gruppierung ${ }^{258}$ zeigten zwar auch viele der französischen Stiftergruppen, waren aber anders als deutsche und englische Komitees gelegentlich eher nach unten geöffnet. Als Spezifikum Londoner Initiatorenzirkel war

${ }^{258}$ Vgl. Hartmut KAELBLE, Französisches Bürgertum und deutsches Bürgertum 1870-1914, in: KoCKA (Hg.), Bürgertum 1, S. 107-140. 
schließlich in fast allen Projekten eine erhebliche Beteiligung adliger Formationen an den Mitgliederversammlungen und konstituierenden Sitzungen zu beobachten, die auf eine besondere Affinität zwischen "middle« und »upper classes « zu verweisen schien $^{259}$. Ein überparteiliches oder parteilich neutralisiertes Erscheinungsbild wurde hier zu einem Signum der Denkmalkomitees und lie $B$ die entsprechenden Vereinigungen damit auch als eine Art moralischen Hort eines national konnotierten Gemeininteresses erscheinen ${ }^{260}$. Neben einer charakteristischen »Mittelklasse«-Bindung erwies sich demzufolge die soziale Exklusion nach unten mit Ausnahme weniger französischer Fälle als Kennzeichen der hauptstädtischen Denkmalbewegung.

${ }^{259}$ Vgl. Eric J. HOBSBAWM, Die englische middle class 1780-1920, in: KoCKA (Hg.), Bürgertum 1, S. 79-106; Willibald STELNMETZ, Gemeineuropäische Tradition und nationale Besonderheiten im Begriff ,Mittelkasse،. Ein Vergleich zwischen Deutschland, Frankreich und England, in: Reinhart KOSELLECK, Klaus SCHREINER (Hg.), Bürgerschaft. Rezeption und Innovation der Begrifflichkeit vom Hohen Mittelalter bis ins 19. Jahrhundert, Stuttgart 1994 (Sprache und Geschichte, 22), S. 161-236.

${ }^{260}$ Vgl. Andreas WIRSCHING, Bürgertugend und Gemeininteresse. Zum Topos der "Mittelklassen « in England im späten 18. und frühen 19. Jahrhundert, in: AKG 72 (1990) S. 173-199. 